Luis Antonio Chávez Pinto

\title{
Modelo estrutural numérico que simula a alocação de absorvedores dinâmicos para redução de ruído acústico emitido por um transformador de potência
}

Dissertação apresentada à Escola Politécnica da Universidade de São Paulo para obtenção do título de Mestre em Engenharia Mecânica. 
Luis Antonio Chávez Pinto

\section{Modelo estrutural numérico que simula a alocação de absorvedores dinâmicos para redução de ruído acústico emitido por um transformador de potência}

Dissertação apresentada à Escola Politécnica da Universidade de São Paulo para obtenção do título de Mestre em Engenharia Mecânica.

Área de concentração:

Engenharia de Controle e Automação Mecânica

Orientador:

Prof. Dr. Raul Gonzalez Lima 
Este exemplar foi revisado e alterado em relação à versão original, sob responsabilidade única do autor e com anuência de seu orientador

São Paulo, 28 de abril de 2008

Assinatura do autor

Assinatura do orientador 


\section{Ficha Catalográfica}

Chávez Pinto, Luis Antonio

Modelo estrutural numérico que simula a alocação de absorvedores dinâmicos para redução de ruído acústico emitido por um transformador de potência. São Paulo, 2008. 65 p.

Dissertação (Mestrado) — Escola Politécnica da Universidade de São Paulo. Departamento de Engenharia Mecânica.

1.Método dos Elementos Finitos 2.Ruído urbano 3.Vibrações 4.Dinâmica(Simulações). I.Universidade de São Paulo. Escola Politécnica. Departamento de Engenharia Mecânica. II. Título. 
Aos meus pais Luis Paul e Maria Elena. 


\section{Agradecimentos}

Agradeço a Deus por ter me acompanhado em todo este tempo fora de casa e por ter me dado forças para suportar muitas vezes a solidão.

Ao meu orientador, Prof. Raul Gonzalez Lima, pelo apoio, paciência, orientação e incentivo ao desenvolvimento acadêmico.

Aos meus familiares, especialmente para meus avós Carlos e Orlanda, a minha irmã Patricia e a minha tia Magda, que a vida já levou.

Aos meus colegas de sala, especialmente a meu colega Elvys pela atenção, partilha e esclarecimento de dúvidas referentes ao trabalho de pesquisa.

Aos meus colegas de trabalho Carlos, Sergio e Louisie. Aos meus amigos brasileiros, colombianos e peruanos pela companhia e os muitos momentos divertidos que passamos. E a todos que direta ou indiretamente contribuíram para a realização deste trabalho. 
"É melhor tentar, ao invés de sentar-se e nada fazer; é melhor falhar, mas não deixar a vida passar; eu prefiro na chuva caminhar, do que em dias tristes em casa me esconder; prefiro ser feliz, embora louco, do que viver infeliz no conformismo"...

Martin Luther King 


\section{Resumo}

Os transformadores de potência elétrica produzem um elevado nível de ruído que em alguns casos gera desconforto à comunidade vizinha. $\mathrm{O}$ presente trabalho desenvolve um modelo estrutural de elementos finitos que, com carregamento adequado, é capaz de reproduzir o deslocamento, medido durante a operação, de um transformador de potência elétrica. Este modelo estrutural é utilizado para calcular a redução do deslocamento das superfícies deste transformador decorrentes do emprego de absorvedores dinâmicos de vibração. Este modelo estrutural foi desenvolvido para estimar o número de absorvedores dinâmicos, sua massa e sua localização que permitiria reduzir o ruído acústico emitido por este transformador de potência até alcançar níveis de intensidade de som em comformidade com a legislação brasileira.

Palavra Chave: Transformador de potência, Ruído industrial, Vibrações, Absorvedor dinâmico, Tanque do transformador. 


\section{Abstract}

Electrical power transformers produce a high level of noise, which, in some cases, generate discomfort to the surrounding community. The present work develops a structural model by the Finite Element Method that, with adequate loading conditions, is capable of reproducing the displacement, measured during operation, of the transformer tank. The structural model has been used to compute the displacement reduction of the transformer surfaces by using dynamic vibration absorbers. The structural model was developed to estimate the number of dynamic absorbers, the mass and localization that could reduce the acoustic noise to levels of intensity of sound in accordance to the Brazilian law.

Keyword: Power transformer, Industrial noise, Vibrations, Dynamic absorber, Transformer tank. 


\section{Sumário}

\section{Lista de Figuras}

\section{Lista de Abreviaturas}

1 INTRODUÇÃO 1

1.1 Transformadores de energia elétrica . . . . . . . . . . . . . . . 3

1.2 Ruído gerado por transformadores . . . . . . . . . . . . . . 5 5

1.2.1 Ruído do núcleo do transformador . . . . . . . . . . . . . . . 6

1.2.2 Ruído causado por forças eletromagnéticas . . . . . . . . . . . 6

1.2.3 Ruído de ventiladores e bombas . . . . . . . . . . . . . . . 6

1.3 Técnicas para controle de vibração e ruído . . . . . . . . . . . . . 7

1.3.1 Controle passivo . . . . . . . . . . . . . 7

1.3.2 Controle ativo . . . . . . . . . . . . . . 8

1.3 .3 Síntese . . . . . . . . . . . . . . . . . . 10

2 OBJETIVOS 12

3 REVISÃO BIBLIOGRÁFICA

4 MEtodologia $\quad 16$

4.1 Medidas de aceleração das faces do Tanque . . . . . . . . . . . . . 17

4.1.1 Geometria do Transformador . . . . . . . . . . . . . . 17

4.1 .2 Aquisição de dados de vibração . . . . . . . . . . . . . . . . . 19

4.2 Tratamento dos sinais de aceleração . . . . . . . . . . . . . . 21 
4.3 Modelagem via Método dos Elementos Finitos . . . . . . . . . . . . . . 23

4.3.1 Modelo do Tanque . . . . . . . . . . . . . . . . . . . . . 23

4.3.2 Modelo de um ADV . . . . . . . . . . . . . . . 26

4.4 Redução da intensidade de ruído acústico . . . . . . . . . . . . . . . . . 27

5 RESULTADOS 29

5.1 Análise do tratamento dos sinais de aceleração . . . . . . . . . . . . . . . . 29

5.2 Análise das faces do tanque do Transformador . . . . . . . . . . . . . . . 31

5.2.1 Análise da face frente aos prédios . . . . . . . . . . . . . . . 31

5.2.2 Análise da face oposta aos prédios . . . . . . . . . . . . . . 32

5.2 .3 Análise da face frente à rua . . . . . . . . . . . . . . . 33

5.2 .4 Análise da face oposta à rua . . . . . . . . . . . . . . . . . . . 34

5.2 .5 Análise da placa base . . . . . . . . . . . . . . . . . 35

5.3 Análise do modelo via MEF . . . . . . . . . . . . . . . . . . . 37

5.3.1 Análise do modelo da face frente aos prédios . . . . . . . . . . . 37

5.3.2 Análise do modelo da face oposta aos prédios . . . . . . . . . . . 39

5.3 .3 Análise do modelo da face frente à rua . . . . . . . . . . . . . . 40

5.3.4 Análise do modelo da face oposta à rua . . . . . . . . . . . . . . . . 42

5.4 Análise da redução de ruído acústico f . . . . . . . . . . . . . . . . . . . 43

6 DISCUSSÃO $\quad 45$

7 COMENTÁRIOS FINAIS $\quad 47$

$\begin{array}{ll}\text { Referências } & 48\end{array}$

Apêndice A - Conceitos utilizados $\quad 50$

A.1 Decibel . . . . . . . . . . . . . . . . . . . 50

A.2 Lei de Lenz . . . . . . . . . . . . . . . . . . . . 51 
A.3 Operating Deflection Shape . . . . . . . . . . . . . . 52

A.4 Parâmetros espectrais . . . . . . . . . . . . . . . . . . 52

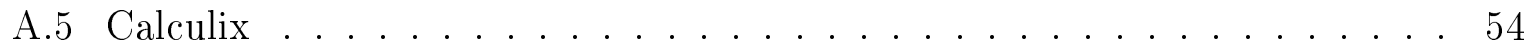

Apêndice B - Modelo com duas massas e duas molas para definir a freqüência do ADV

Apêndice C - Código fonte - Tratamento dos Sinais 58

Apêndice D - Arquivo de entrada para o CalculiX 


\section{Lista de Figuras}

1.1 Núcleo de um Transformador . . . . . . . . . . . . . . . . . . . . . . 3

1.2 Tanque de um transformador . . . . . . . . . . . . . . . . . . 4

1.3 Montagem do núcleo e enrolamentos . . . . . . . . . . . . . . . 5

1.4 Campo Acústico de um transformador no plano vertical . . . . . . . . . . . . 9

1.5 Campo Acústico de uma subestação no plano horizontal . . . . . . . . . 9

4.1 Transformador regulador de potência 30/40 MVA, 138-13,8/11,95 kV . . . 17

4.2 Geometria do tanque do transformador . . . . . . . . . . . . . . . . . 18

4.3 a) Esquema da face frente à rua; b) Esquema da face frente aos prédios . . 19

4.4 Localização da Subestação Bela Aliança . . . . . . . . . . . . . . . . . . . 19

4.5 Representação da localização dos acelerômetros na face do transformador oposta à rua . . . . . . . . . . . . . . . . . . . . . . . . 20

4.6 Esquema representativo do processamento dos sinais . . . . . . . . . . . . 21

4.7 Elemento hexaédrico C3D20 (20 nós) . . . . . . . . . . . . . . . . 24

4.8 Malha do tanque do transformador . . . . . . . . . . . . . . 25

4.9 Esquema do carregamento de forças de uma face do modelo do tanque . . . 25

4.10 Modelo do ADV . . . . . . . . . . . . . . . . . . . . 26

4.11 Malha do ADV . . . . . . . . . . . . . . . . 26

4.12 Esquema representativo de união de um ADV ao tanque . . . . . . . . . 27

5.1 Modelo geométrico mostrando o deslocamento da superfície do tanque $01 d B$-Brasil . . . . . . . . . . . . . . . . . . . 29

5.2 Espectros de freqüência da correlação cruzada . . . . . . . . . . . . . . . 30

5.3 Face da placa base situada abaixo do tanque . . . . . . . . . . . . 30 
5.4 Face frente aos prédios máxima amplitude positiva $\ldots \ldots$. . . . . . . . 32

5.5 Face frente aos prédios mínima amplitude negativa . . . . . . . . . . . 32

5.6 Face oposta aos prédios máxima amplitude positiva . . . . . . . . . . . . 33

5.7 Face oposta aos prédios mínima amplitude negativa . . . . . . . . . . . . 33

5.8 Face frente à rua máxima amplitude positiva . . . . . . . . . . . . . . . . . 34

5.9 Face frente à rua mínima amplitude negativa . . . . . . . . . . . . . . . . 34

5.10 Face oposta à rua máxima amplitude positiva . . . . . . . . . . . . . 35

5.11 Face oposta à rua mínima amplitude negativa . . . . . . . . . . . . . 35

5.12 Face da placa base máxima amplitude positiva . . . . . . . . . . . 36

5.13 Face da placa base mínima amplitude negativa . . . . . . . . . . . . 36

5.14 Potência média de deslocamento da face frente aos prédios . . . . . . . . 38

5.15 Porcentagem da queda da potência média de deslocamento na face frente aos prédios . . . . . . . . . . . . . . . . . . . . . 38

5.16 Potência média de deslocamento da face oposta aos prédios . . . . . . . . . 39

5.17 Porcentagem da queda de potência média de deslocamento na face oposta aos prédios . . . . . . . . . . . . . . . . . . . . . 40

5.18 Potência média de deslocamento da face frente à rua . . . . . . . . . . . 41

5.19 Porcentagem da queda de potência média de deslocamento na face frente à rua . . . . . . . . . . . . . . . . . . . . . . . . 41

5.20 Potência média de deslocamento da face oposta à rua . . . . . . . . . . . . 42

5.21 Porcentagem da queda de potência média de deslocamento na face oposta à rua . . . . . . . . . . . . . . . . . . . . . . . . 43

5.22 Redução da intensidade de ruído acústico . . . . . . . . . . . . . . . . . 44

B.1 Esquema do modelo utilizando ADV amortecido . . . . . . . . . . . . . 56 


\section{Lista de Abreviaturas}

ABNT Associação Brasileira de Normas Técnicas

ADV Absorvedor Dinâmico de Vibração

ANC Controle ativo de ruído

AVC Controle ativo de vibração

ASAC Controle ativo acústico-estrutural

CAD Desenho Auxiliado por Computador

CONAMA Conselho Nacional do Meio Ambiente

FFT Transformada Rápida de Fourier

FRF Função de Resposta em Freqüência

GDL Grao de Liberdade

IFFT Transformada Inversa de Fourier

MEC Método dos Elementos de Contorno

MEF Método dos Elementos Finitos

NBR Normas Brasileiras

ODS Operating Deflection Shape (Forma de Deflexão Operacional)

OMS Organização Mundial de Saúde

SE Subestação Elétrica

TDF Transformada Discreta de Fourier 


\section{INTRODUÇÃO}

Este trabalho surge como conseqüência do elevado nível de ruído gerado por transformadores de alta potência, que causam desconforto à comunidade próxima, como ocorre, por exemplo, na subestação Bela Aliança (Eletropaulo) em São Paulo.

A transmissão de energia elétrica visando diminuir os custos é realizada em tensões elevadas, quando a energia chega aos centros de consumo tem sua tensão rebaixada para tensões compatíveis com os sistemas de distribuição. Para alterar a tensão faz-se uso de transformadores. Estes transformadores integram com outros equipamentos as subestações (BURIAN, 1991). As subestações são fontes de ruído acústico e o principal causador é o transformador. Normalmente, as subestações situam-se longe de centros urbanos evitando gerar impacto ambiental sobre a população, com o crescimento e ocupação desordenada das grandes cidades, áreas residenciais vem se aproximando às subestações chegando a envolvê-las (FARIAS et al., 1997).

Ruído acústico é um tipo de poluição sonora, uma das formas de poluição ambiental que vem se agravando atualmente. Em âmbito federal, o Conselho Nacional do Meio Ambiente (CONAMA) estabelece que são prejudiciais à saúde e ao sossego público ruídos com níveis superiores aos regidos pela norma NBR 10151 (ABNT, 2000). Esta norma estabelece para ambientes internos com janelas abertas em zonas residenciais urbanas o nível máximo de $45 \mathrm{~dB}(\mathrm{~A})$ para o período diurno (das $6 \mathrm{~h}$ às $20 \mathrm{~h}$ ) e de $40 \mathrm{~dB}(\mathrm{~A})^{1}$ para o período noturno (das $20 \mathrm{~h}$ às $6 \mathrm{~h}$ ). A Organização Mundial de Saúde (OMS) recomenda que durante o sono o ruído de fundo não deva exceder $30 \mathrm{~dB}(\mathrm{~A})$ (wHO, 2004). O ruído produzido por um transformador tem ao longo do dia aproximadamente a mesma intensidade, entre 60dB(A) e 70dB(A) (MEDEIROS; KROEFF, 1998), fazendo com que o horário crítico da geração de ruído ocorra durante a noite. Este fato exige o desenvolvimento de tecnologia para controlar o ruído emitido e minimizar efeitos nocivos à qualidade de vida dos cidadãos (UCB, 2001).

\footnotetext{
${ }^{1}$ ver Apêndice - A.1
} 
A preocupação com o ruído audível emitido por equipamentos elétricos dentro de ambientes industriais surgiu no início do século XX, mas o estudo sistemático do comportamento acústico de subestações elétricas teve início na década de 1960. Assim, durante as décadas seguintes o ruído de transformadores é investigado e tem diminuído consideravelmente (RODRIGUES; MEDEIROS; PAVANELLO, 1998). No Brasil, estes estudos são mais recentes, com os primeiros trabalhos datados da década de 1980. Com o crescimento das cidades e maior preocupação com a lei ambiental, é a partir de 1990 que começaram os primeiros projetos de adequação do nível de ruído nas subestações (FERREIRA, 2006).

Na maioria dos transformadores atualmente em funcionamento o núcleo é apoiado diretamente na carcaça, transmitindo as vibrações para a mesma e seus sistemas auxiliares. O fluido de arrefecimento também pode transmitir vibração para o tanque do transformador.

Há vários métodos para redução de ruído e vibrações. Vários métodos ocorrem na fase de projeto de um transformador novo. Por exemplo, pode ser projetada uma suspensão entre o núcleo e o tanque ou são empregados desenhos especiais para as lâminas metálicas que compõem o núcleo. Entretanto, o parque instalado de transformadores no Brasil é numeroso e ainda deve durar por muitos anos. Entre os métodos de redução de ruído em transformadores já instalados podemos citar o uso de amortecedores, o uso de edificação em torno do transformador, o cancelamento ativo de ruído acústico e o uso de absorvedores dinâmicos. Há ainda controvérsia sobre a capacidade de cada método de reduzir ruído acústico emitido e em quais condições cada método é aplicável com eficácia e boa relação custo/benefício.

Um absorvedor dinâmico é essencialmente um sistema de uma massa e uma mola. Este sistema massa mola tem freqüência tal que a energia cinética da base, numa faixa estreita de freqüência, acaba sendo transmitida para a massa do absorvedor. Desta forma os absorvedores dinâmicos são recomendados quando problemas de vibração ocorrem sobre uma faixa estreita de freqüência (BIES; HANSEN, 1996). A parte da energia cinética do tanque que é transferida para o absorvedor dinâmico se acopla fracamente com o ar (HARTOG, 1972), resultando uma redução do ruído acústico emitido.

A seguir apresentam-se conceitos básicos sobre transformadores, uma breve explicação sobre as fontes predominantes de ruído em transformadores e são descritas algumas técnicas de controle utilizadas para solucionar este tipo de problemas. 


\subsection{Transformadores de energia elétrica}

Segundo Martignone (1971), transformadores de energia elétrica são máquinas estacionárias quase estáticas, que tem como princípio de funcionamento os fenômenos descritos na Lei de Lenz ${ }^{2}$, e como função principal elevar ou reduzir a tensão de transporte, distribuição e consumo das redes de energia elétrica. Para isso, os transformadores são compostos por enrolamentos eletricamente isolados, acoplados através de um núcleo magnético comum, onde circula uma corrente alternada responsável pela variação do fluxo magnético; que quando utilizados para elevados níveis de potência e tensão (característicos dos sistemas de transmissão de grandes quantidades de energia elétrica) são denominados transformadores de alta potência, transformadores de potência ou transformadores de força.

Esta seção segue de perto o manual do transformador manufaturado pela Siemens e instalado na subestação de Bela Aliança Siemens Ltda (2001). Os transformadores de alta potência segundo o manual, são constituídos basicamente dos seguintes componentes:

- Núcleo Magnético: Transformadores de força tem núcleo envolvido, as colunas estão dispostas em um plano e interligadas pelas culatras. A Fig. 1.1 mostra o núcleo de um transformador de 135 MVA em construção especial para baixo nível de ruído de $55 \mathrm{~dB}(\mathrm{~A})$, que é composto pelo empilhamento de lâminas de liga Ferro-Silício (1,5 a $3 \%$ de Si) tipo grão orientado, com espessuras da ordem de 0,23 a $0,30 \mathrm{~mm}$.

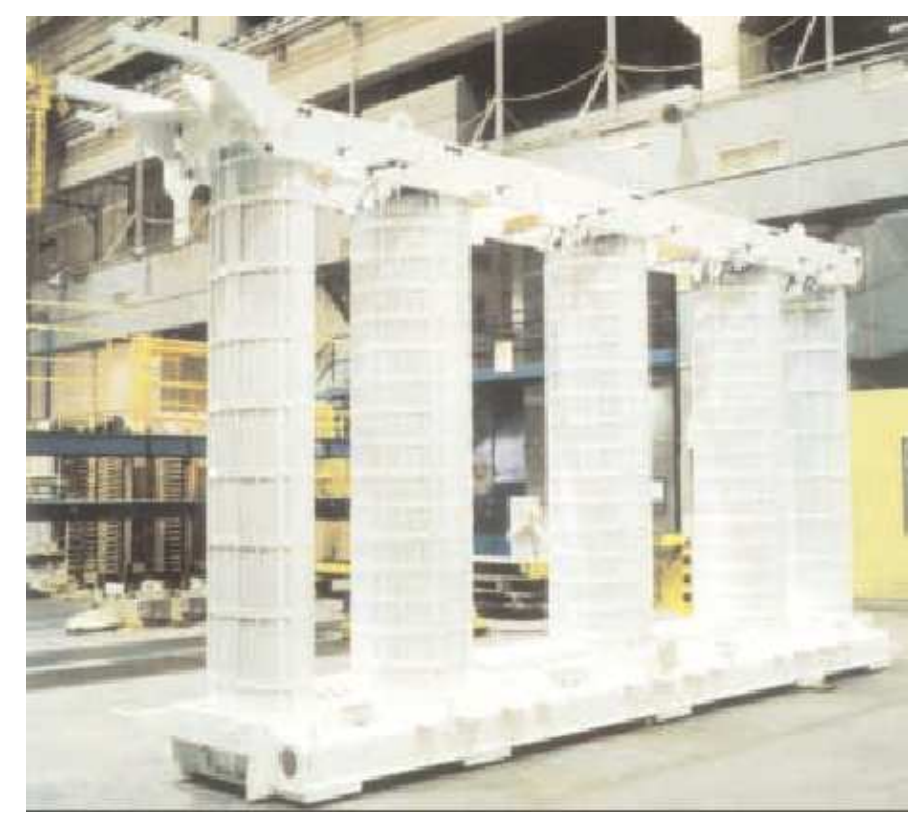

Figura 1.1: Núcleo de um Transformador

\footnotetext{
${ }^{2}$ ver Apêndice - A.2
} 
- Enrolamentos: O material condutor empregado nos enrolamentos de transformadores de força é cobre de seção normalmente retangular. O tipo de enrolamento depende da potência e tensão. Enrolamentos em discos são preferidos para tensões mais altas, eles se constituem de discos simples ou de enrolamento contínuo com dutos radiais e axiais para a refrigeração pelo óleo mineral. Para tensões mais baixas é usual o emprego de enrolamentos em camadas, são camadas simples dispostas de forma concêntrica uma acima da outra, separadas por dutos axiais.

- Variação de Tensão: Para adequar a relação de tensão às condições do sistema, o transformador está provido de um enrolamento especial com derivações. A relação de tensão pode ser alterada através de um comutador em vazio estando o transformador desenergizado ou por um comutador de derivações em carga com o transformador energizado. Acionamentos motorizados são usados para operar os comutadores, possibilitando comando local ou à distância inclusive com controle automático de tensão.

- Tanque: O tanque aloja a parte ativa do transformador (núcleo e enrolamentos), assim como o óleo isolante. Seu peso muitas vezes é de dezenas de toneladas. As chapas de aço tem espessuras variadas, adequadas ao tamanho, formato do tanque e às condições de transporte que muitas vezes representam altíssimos esforços mecânicos. Mesmo sob as condições mais severas incluindo o vácuo, o tanque deve apresentar segurança e estanqueidade (ver Fig. 1.2). A solda e o acabamento interno e externo do tanque são importantes para a performance do transformador.

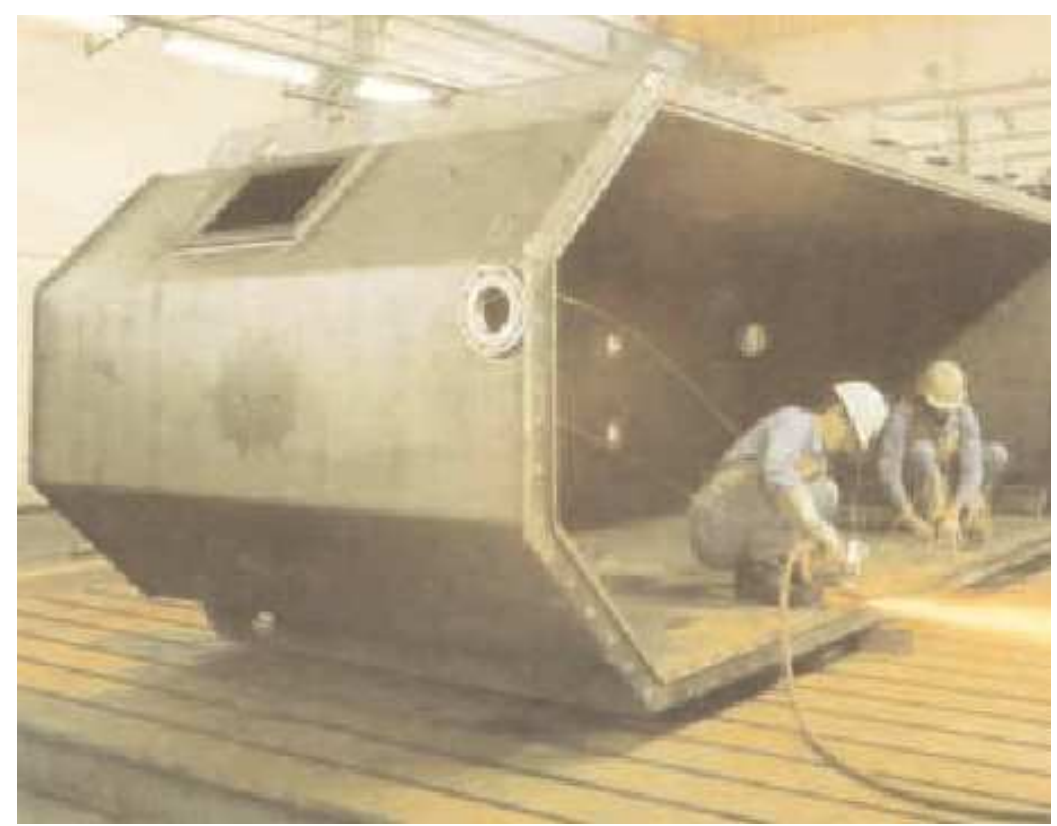

Figura 1.2: Tanque de um transformador 
- Refrigeração: A eficiência da refrigeração é um fator fundamental que determina a segurança operacional e o tempo de vida de um transformador. O sistema utilizado com maior freqüência em unidades menores é a refrigeração natural, onde o calor é absorvido pelo óleo e dissipado no ar através de radiadores. Em outros sistemas os radiadores são adicionalmente refrigerados por meio de ventiladores. O sistema de refrigeração pode também consistir de bancos de radiadores separados ou com trocador óleo/água. A refrigeração pode ainda ser implementada por meio do fluxo direcionado do óleo.

Na área de montagem, as peças que compõem a parte ativa do transformador são conjugadas para colocação dentro do tanque como uma peça única constituída do núcleo, enrolamentos, ferragens, comutador de derivações, terminações, etc. Antes de ser colocada no tanque, a parte ativa completamente montada é seca em câmara especial de vaporphase. O enchimento com óleo mineral isolante é realizado sob vácuo, posteriormente, os acessórios como acionamento motorizado, quadros de controle, buchas, dispositivos de comando, etc; são afixados ao tanque (SIEMENS LTDA, 2001). A Fig. 1.3 mostra a montagem do núcleo e enrolamentos (parte ativa completa de um transformador de 135 MVA com comutador em carga).

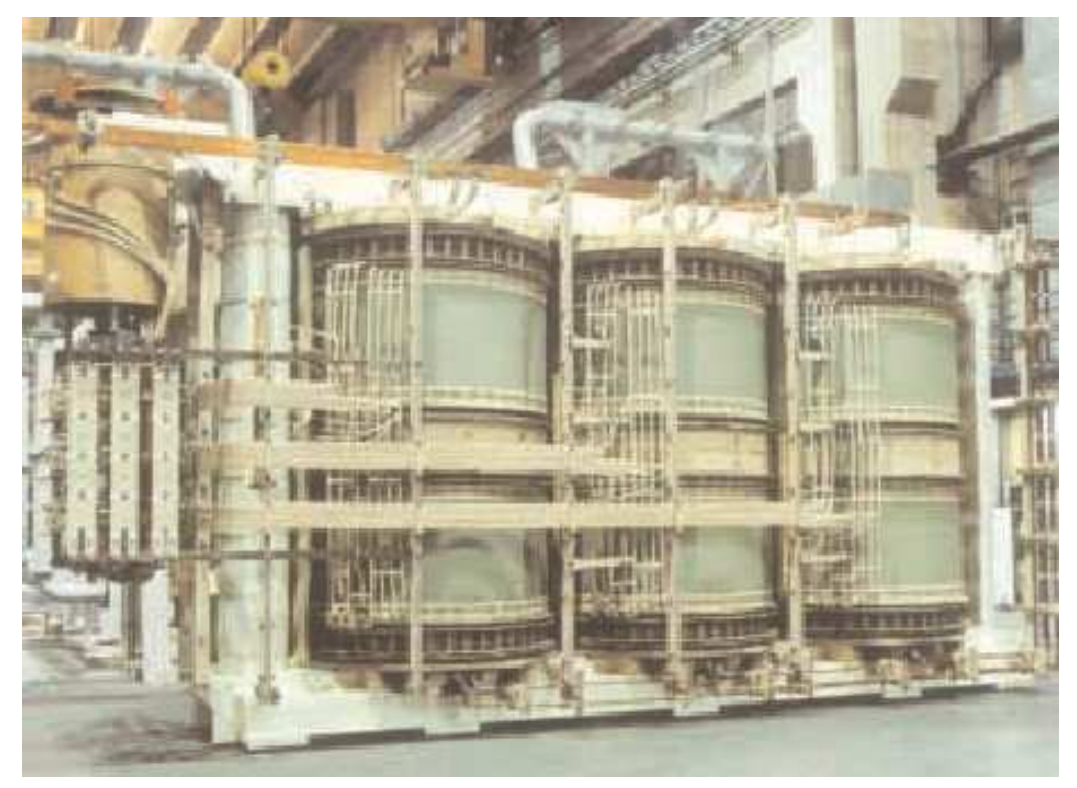

Figura 1.3: Montagem do núcleo e enrolamentos

\subsection{Ruído gerado por transformadores}

As fontes predominantes do ruído em transformadores, segundo (IEEE, 2000), são, 
- ruído no núcleo causado por forças eletromagnéticas e forças magnéticas interlaminares;

- ruído causado por forças eletromagnéticas nos enrolamentos, nas paredes do tanque, e nas derivações magnéticas devido às perdas do fluxo associadas com a corrente;

- ruído dos equipamentos de refrigeração causados por ventiladores e bombas.

\subsubsection{Ruído do núcleo do transformador}

Quando as lâminas do núcleo são magnetizadas, estas sofrem pequenas mudanças nas suas dimensões. Este fenômeno é chamado de magnetoestricção e é independente da direção do fluxo; por conseguinte, este ocorre no dobro da freqüência da linha elétrica $(120 \mathrm{~Hz})$. Já que a curva de magnetoestricção é não-linear, harmônicos de ordem maior (240-360-480...Hz) aparecem na vibração resultante.

\subsubsection{Ruído causado por forças eletromagnéticas}

A fonte destes ruídos são as vibrações das paredes do tanque, os protetores magnéticos, e os próprios enrolamentos. São predominantemente produzidas por vibrações axiais e radiais nos enrolamentos do transformador. Em alguns casos, a freqüência natural dos enrolamentos pode ser próxima da freqüência de excitação das forças eletromagnéticas, desse modo, intensifica-se severamente a amplitude de vibração e conseqüentemente de ruído acústico.

\subsubsection{Ruído de ventiladores e bombas}

O ruído do sistema de ventilação, geralmente é encoberto pelo ruído gerado pela vibração electromecânica do transformador. Os ventiladores utilizados no sistema de refrigeração dos transformadores, só contribuem ao ruído total em pequenos transformadores e de baixa indução. Alguns fatores que afetam a saída do ruído total nos ventiladores, são: velocidade de rotação, desenho das pás, número de pás, entre outros. O ruído produzido pelas bombas é normalmente insignificante se o ventilador está em funcionamento, entretanto, ruídos em baixas freqüências podem ser gerados.

O espectro de freqüência do ruído produzido no núcleo e enrolamentos, tem marcada diferença ao produzido nos equipamentos de refrigeração, enquanto no último predominam 
baixas e elevadas freqüências, no primeiro predomina freqüências intermediárias (entre 100 e $600 \mathrm{~Hz})$.

\subsection{Técnicas para controle de vibração e ruído}

Segundo Huang e Fuller (1997), muitas técnicas tem sido desenvolvidas para reduzir a vibração e ruído acústico, estas técnicas podem ser classificadas como segue,

- técnicas de controle passivo;

- técnicas de controle ativo.

\subsubsection{Controle passivo}

Controle passivo tem sido a classe de técnicas tradicionais para reduzir ruído. A vibração e o ruído acústico é reduzido adicionando apropriados elementos passivos ou modificando a estrutura. (FILIPPIN et al., 2003) e (JASINSKI et al., 2005) argumentam que dentro das técnicas passivas existem basicamente quatro formas para reduzir os níveis de vibração e ruído,

- reduzir o nível de vibração na fonte, atuando sobre o núcleo, isolando-o mecanicamente da carcaça que o contém, isolando os trocadores de calor da carcaça do transformador e isolando as caixas de controle e fusíveis;

- fazer modificações estruturais na carcaça para evitar o fenômeno de ressonância;

- reduzir o nível de ruído na trajetória, isolar o ruído do transformador enclausurandoo ou através de barreiras e defletores;

- introduzir absorvedores dinâmicos de vibração (ADVs).

\subsubsection{Absorvedor dinâmico de vibração}

Absorvedores dinâmicos de vibração são essencialmente dispositivos de parâmetros concentrados de massa, rigidez e amortecimento. Que uma vez acoplados a uma estrutura são capazes de absorver a energia vibratória no ponto de conexão (CUNHA, 1999).

Desde sua invenção por Frahm (1911) no início do século 20, os ADVs têm sido utilizados para atenuar vibrações em diversos tipos de máquinas e estruturas. Além do ADV 
de Frahm constituído de um sistema de 1 Grao de Liberdade (GDL) com amortecimento viscoso, também têm sido utilizados sistemas estruturais discretos de vários GDL (RAM; ELHAY, 1996) e sistemas contínuos (CUNHA, 1999). Um estudo abrangente da teoria e aplicações práticas dos ADVs é apresentado por (KORONEV; REZNIKOV, 1993).

Segundo Cunha (1999) os parâmetros de inércia, rigidez, e amortecimento, são escolhidos enquanto os ADVs são sintonizados para atenuação de vibrações harmônicas com uma freqüência de excitação fixa. Assim, estes dispositivos tendem a perder eficiência quando a freqüência de excitação for alterada (mesmo que ligeiramente). Para contornar este problema é necessário determinar parâmetros que garantam amplitudes mínimas de vibração em uma banda de freqüência (a mais larga possível), este procedimento é conhecido como de otimização do ADV.

\subsubsection{Controle ativo}

Os métodos de controle ativo tornaram-se cada vez mais populares, com o desenvolvimento recente em técnicas de processamento de sinais digitais. O controle de vibrações e ruído em tempo real estão se tornando muito efetivos utilizando programas computacionais de cálculo rápido. Técnicas de controle ativo tem sido usados para reduzir a vibração de estruturas e o ruído resultante.

No controle ativo de ruído (Active Noise Control-ANC) são empregados microfones com sensores de erro e fontes acústicas para reduzir o ruído acústico. No controle ativo de vibração (Ative Vibration Control-AVC) são utilizados sensores de erro estruturais e atuadores de força para reduzir vibrações estruturais. O uso de AVC não necessariamente assegura redução do ruído, freqüentemente o uso de AVC pode incrementar a radiação sonora, nestes casos, o controle ativo acústico-estrutural (Active Structural-Acoustic Control- $A S A C$ ) é usado, onde entradas de vibração são empregadas conjuntamente com sensores de erro acústico para solucionar este tipo de problema.

Já que o procedimento para a técnica de controle ativo baseia-se no conhecimento da resposta dinâmica das chapas externas, dos trocadores de calor, e do tanque do transformador; o conhecimento global do campo acústico é uma condição prévia para a análise do problema.

O campo acústico de um transformador mostrado na Fig. 1.4 e o campo acústico de uma subestação elétrica na Fig. 1.5 foram apresentados por (RAUSCH et al., 2002) e (MEDEIROS; KROEFF, 1998) respectivamente, utilizando os métodos de elementos finitos 
e elementos de contorno. Nestes gráficos se observa o efeito do campo acústico que pode provocar um transformador dentro de uma subestação elétrica, com o qual pode-se avaliar o impacto acústico em zonas residenciais vizinhas. As soluções são obtidas através de dados experimentais e simulações computacionais.

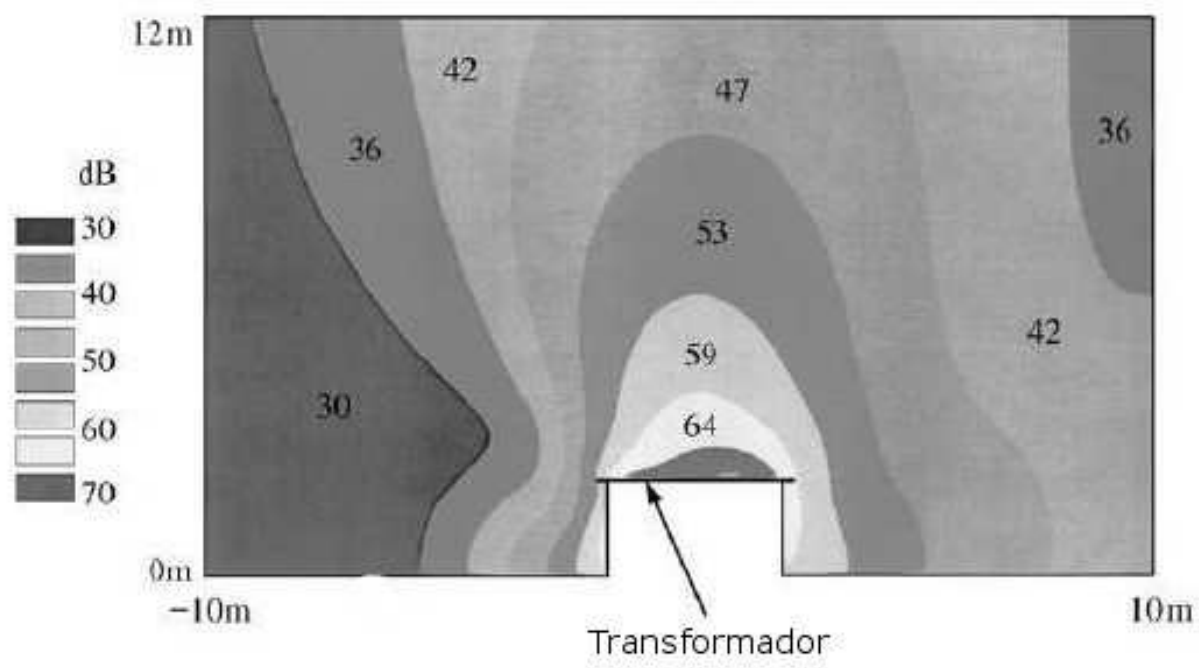

Figura 1.4: Campo Acústico de um transformador no plano vertical

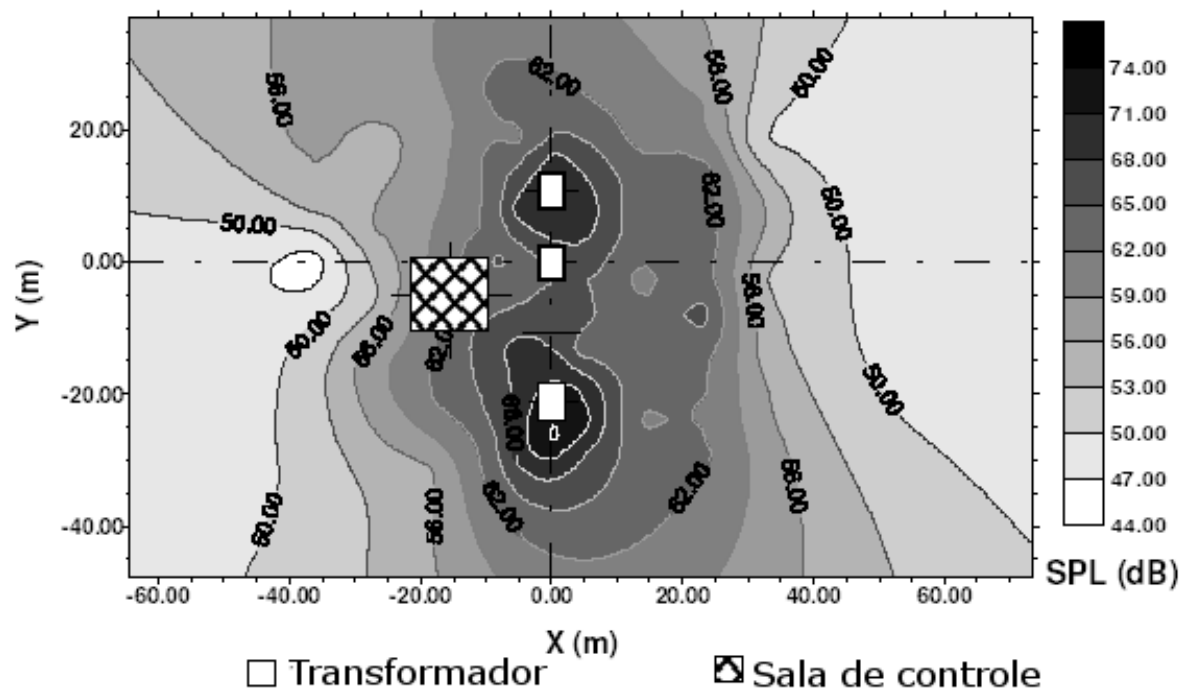

Figura 1.5: Campo Acústico de uma subestação no plano horizontal

Segundo o manual da IEEE (2000), dentro das técnicas ativas para redução de ruído gerado por transformadores estão,

- cancelamento do campo acústico próximo ao tanque;

- cancelamento do campo acústico distante ao tanque; 
- cancelamento de ruído no interior do tanque;

- supressão harmônica pelo cancelamento do fluxo.

\subsubsection{Cancelamento do campo acústico próximo ao tanque}

O cancelamento do campo acústico próximo ao tanque do transformador pode ser conseguido colocando diversos alto-falantes próximos ao tanque, separados em uma distância curta (distância menor que o comprimento da onda acústica de interesse), criando assim, um som com 180 graus fora de fase (anti-som) em relação ao som irradiado pelo transformador. Outras formas de cancelamento usando o mesmo princípio é a utilização de atuadores de deslocamento, os quais podem ser colocados diretamente na parede do tanque para alterar a forma da deflexão em freqüências específicas e por conseguinte diminuir o ruído acústico produzido.

O desempenho deste sistema depende de vários fatores tais como: local do terreno, condições do tempo, flutuações ambientais da temperatura e complexidade geométrica do transformador. Não há relatos de resultados satisfatórios deste procedimento.

\subsubsection{Cancelamento do campo acústico distante ao tanque}

O cancelamento do campo acústico distante consta de diversos atuadores acústicos, os quais estão localizados geralmente entre 1.3 - 2 m distantes do transformador. Já que neste caso o transformador encontra-se distante, os atuadores acústicos devem cobrir uma área de superfície maior em relação à técnica anterior. Além disso, pode apresentar necessidade de controlar a fase do deslocamento induzido pelo vento, entre o som original e o anti-som. Estes fatores fazem que o cancelamento do campo acústico distante seja uma técnica muito mais cara e complicada. Na prática torna-se difícil criar um modelo uniforme zona tranqüila com a utilização desta técnica. Contraditóriamente, os níveis sonoros podem mesmo aumentar em determinados locais devido à presença do anti-som. Também não há relatos satisfatórios desta técnica.

\subsubsection{Síntese}

Em conclusão as técnicas de controle acústico ativo não tem apresentado resultados satisfatórios nestes espaços abertos. O controle passivo vem sendo uma ferramenta importante do controle da vibração e o ruído. Comparado ao controle ativo exibe as vantagens de 
execução fácil, baixo custo de manutenção e nenhuma necessidade de utilização de energia externa. 


\section{OBJETIVOS}

Este trabalho tem como objetivo estimar a redução de ruído acústico possível emitido por um transformador de potência trifásico através do emprego de absorvedores dinâmicos, considerando estabelecidas as seguintes condições

1. os absorvedores dinâmicos terão todos a mesma massa;

2. os absorvedores dinâmicos serão fixados um de cada vez. O primeiro absorvedor dinâmico será fixado no ponto de maior amplitude de deslocamento de uma face. Os novos deslocamentos da face serão calculados e no novo ponto de maior deslocamento será afixado o segundo absorvedor dinâmico. Este procedimento será repetido para determinar o número e a localização dos absorvedores dinâmicos;

3. o modelo de carregamento de cada face será proporcional ao deslocamento medido em cada face com o transformador em operação.

Este procedimento visa imitar um procedimento realizável em um transformador real e em operação. Leva em consideração a complexidade geométrica dos tanques, o desconhecimento de como ocorre de fato o carregamento estrutural do tanque e a necessidade de um procedimento experimental para a localização dos absorvedores dinâmicos. 


\section{REVISÃO BIBLIOGRÁFICA}

Neste capítulo apresentam-se resumidamente a revisão dos trabalhos publicados sobre redução de ruído acústico emitido por transformadores.

Um estudo em transformadores foi desenvolvido por (JASINSKI et al., 2005) em um transformador Brown Boveri (AF 1988)-75 MVA-230/138/13,8 kV e outro transformador WEG 2001-5/7 MVA-34,5/13,8 kV. Nestes transformadores foram realizadas medidas de resposta em freqüência; onde a densidade modal obtida foi elevada, isso deu origem, a elevados níveis de vibração tanto na freqüência fundamental $(120 \mathrm{~Hz})$ como em suas freqüências harmônicas. Concluíram que o tanque e os subsistemas dos transformadores amplificam as vibrações geradas pelo núcleo, tanto em uma ou em outra freqüência, dependendo do ponto de resposta da estrutura. Nessa mesma publicação estudaram um transformador em operação, no qual realizaram-se medidas dos níveis de vibração (respostas no domínio das freqüências), utilizando uma malha previamente definida na qual foi possível fazer um mapeamento mostrando os pontos de máxima e mínima vibração, assim como as freqüências predominantes. O cálculo da massa total projetada por Jasinski et al. (2005) para o ADV foi determinado através de uma porcentagem (10 a 20\%) da massa modal do sistema a controlar, de forma equivalente a um sistema de um grau de liberdade, e dos modos de vibrar associados ás freqüências naturais do sistema primário que se encontram na faixa da freqüência de interesse.

Para conseguir obter o material viscoelástico do ADV fizeram diferentes estudos no Laboratório de Vibrações e Acústica da Universidade Federal de Santa Catarina, o qual permitiu escolher o material que melhor se ajustava ao projeto em estudo. Como o material é exposto ao meio ambiente, mudanças na temperatura poderiam dessintonizá-lo das freqüências características e poderia levá-los a trabalhar em condições não ótimas. (JASINSKI et al., 2005) concluíram que o neprone e a borracha butílica com $80 \%$ de Ethylene propylene diene monomer são os mais estáveis a variação de temperatura; por outro lado a borracha butílica pura sendo mais sensível ás variações térmicas, possui um fator de amortecimento maior tornando-a mais eficiente em uma banda ampla de freqüências. O ADV 
projetado conseguiu reduzir a vibração em transformadores pequenos (transformadores de distribuição) em 20 dB, redução considerável para esse tipo de problemas.

(MIZOKAMI; YABUMOTO; OKAZAKI, 1997) analisaram a vibração do núcleo de um transformador trifásico, onde um sistema de medição da vibração utilizando um laser Doppler foi desenvolvido. A vibração ocorreu principalmente nos membros do núcleo, e o sentido da vibração era perpendicular ao plano do núcleo; as diferentes ondas de vibração ocorrem fora da fase entre o membro central e ambos membros laterais. Estes resultados revelaram, que a vibração do núcleo ocorre em um modo específico. Parte da vibração decorre da magnetoestriç̧ão dos membros laterais. A causa da vibração no meio foi considerada sendo gerada pela magnetoestricção sob a magnetização rotatória que ocorre na área da junção-T de um transformador de 3 fases.

(REYNE; MAGNIN; BERLIAT, 1994) desenvolveram um algoritmo para calcular o ruído emitido a partir do campo eletromagnético. A partir do cálculo do campo elétrico e magnético foi possível calcular vibrações mecânicas. A partir do campo de vibração mecânica foi possível calcular o campo acústico. Dados experimentais dos campos magnético, mecânico, e acústico foram comparados com os resultados das computações em 3D. Utilizaram três processadores de elementos finitos, FLUX3D para a parte eletromagnética, SYSTUS para obter a parte mecânica, e $A S T R Y D$ para a parte acústica. Finalmente, utilizaram o programa FLYSTRYD para poder superar as dificuldades na ligação dos programas anteriormente mencionados.

(RAUSCH et al., 2002) apresentaram um modelo de transformadores trifásicos com isolamento de óleo. Este modelo permitiu a computação eficiente dos campos eletromagnéticos, mecânicos, e acoplamentos acústicos. As equações foram resolvidas usando o método dos elementos finitos (MEF), assim como o método dos elementos de contorno (MEC). O modelo permitiu estudar o complexo comportamento dinâmico dos transformadores. A validade das simulações do computador puderam ser verificadas através de medições.

Um estudo experimental para redução de ruído em transformadores de $100 \mathrm{kVA}$ foi realizado por (HESSELMANN, 1978). Ele argumenta que há uma dificuldade em implementar soluções teóricas sob circunstâncias práticas, as fontes de ruído excitam uma faixa ampla de freqüências. As superfícies irradiadas pelo ruído tem forma complexa, e o campo de velocidade não mostra nenhuma simetria, nem mesmo em baixas freqüências.

(GARCíA; BURGOS; ALONSO, 2006) apresentam um estudo onde foi desenvolvido um método para detectar deformações nas bobinas em transformadores de alta potência. $\mathrm{O}$ 
modelo foi desenvolvido para calcular vibrações no tanque, tendo em conta a condição operativa do transformador. Foi tomado em conta como as vibrações são geradas por diferentes componentes. O modelo inclui também, o efeito da temperatura na geração da vibração, e como a vibração é transmitida até o tanque. O cálculo foi realizado para determinar os melhores pontos para fixar acelerômetros na medição da vibração do tanque. Este teste concluiu que os parâmetros do modelo dependem do modo de refrigeração.

(HUANG; FULLER, 1997) estudaram a vibração e o acoplamento do campo acústico em um tanque cilíndrico fechado. Esta vibração foi ocasionada por forças pontuais e por forças distribuídas. Múltiplos absorvedores dinâmicos foram adicionados ao tanque para reduzir a vibração e o conseqüente ruído acústico. A resposta dinâmica do tanque e a pressão acústica na cavidade interior sob a influência dos absorvedores foram obtidas usando as técnicas de sub-estruturação e superposição modal. Os resultados mostraram que a adição de absorvedores dinâmicos corretamente posicionados, podem reduzir satisfatoriamente a vibração do tanque e o campo acústico emitido. Os efeitos da variação dos parâmetros do absorvedor como: massa, coeficiente de rigidez e posicionamento dos absorvedores foram investigados para os dois tipos de forças externas.

(GARCIA-SOUTO; LAMELA-RIVERA, 2002), apresentaram um experimento com a finalidade de comparar os resultados obtidos na medição de ruídos em transformadores por sensores internos ao equipamento, com sinal transmitido por fibra-ótica e os acelerômetros comuns externos. Cita as condições adversas internas tais como imersão em óleo, altas temperaturas e intenso campo eletromagnético. O experimento foi desenvolvido para ruídos na faixa de $100 \mathrm{~Hz}$ (dobro da freqüência do sistema elétrico na Europa), e as respectivas freqüências harmônicas de 200-300-400...Hz. Apresentaram gráficos comparativos e condições de boa aplicabilidade futura. 


\section{METODOLOGIA}

Neste capítulo descreve-se a metodologia utilizada na realização deste trabalho, são descritos os parâmetros necessários para a aquisição e processamento de sinais de vibração. Descreve-se o procedimento para desenvolver o modelo computacional do transformador e do absorvedor dinâmico de vibrações via MEF.

Uma vez que o objetivo deste trabalho é avaliar a redução de ruído acústico emitido por um transformador real em operação através de uma simulação numérica, serão necessários dados de deslocamento do tanque durante a operação do transformador, um modelo numérico do tanque, um modelo numérico de um absorvedor dinâmico, um modelo de carregamento que, dentro de certa precisão, reproduza os deslocamentos medidos, e uma rotina para calcular a redução da intensidade de ruído acústico. Uma metodologia que permite avaliar esta redução de ruído pode ser sub-dividida nas seguintes etapas,

- coletar dados das características geométricas do transformador em estudo;

- coletar sinais de aceleração na superfície do tanque durante a operação do transformador, estes dados devem ser digitalizados para análise, através da técnica ODS ${ }^{1}$;

- o deslocamento na freqüência de interesse, obtido por ODS, deve ser reproduzido em um modelo via método dos elementos finitos, através de forças nodais proporcionais aos deslocamentos medidos;

- através do MEF devem ser obtidos parâmetros de massa e coeficiente de rigidez do modelo que represente o absorvedor dinâmico de vibração tal que sua freqüência natural seja um pouco superior à freqüência de excitação de interesse, $120 \mathrm{~Hz}^{2}$;

- incorporar um modelo do ADV em cada face do modelo MEF do tanque no ponto de maior deslocamento e calcular o novo campo de deslocamentos em cada face do transformador;

\footnotetext{
${ }^{1}$ Operating Deflection Shape, ver Apêndice - A.3

${ }^{2}$ há uma justificativa deste valor no Apêndice - B
} 
- incorporar mais um modelo do ADV em cada face do modelo MEF do tanque no novo ponto de maior deslocamento e calcular o novo campo de deslocamentos em cada face do transformador;

- repetir o ítem anterior calculando sempre a redução da potência média de desloca$m_{e n t}{ }^{3}$ em cada face do tanque, sem incluir a potência média de deslocamento nos ADVs;

- devem ser modificada a massa dos ADVs e os três ítens anteriores devem ser repetidos;

\subsection{Medidas de aceleração das faces do Tanque}

A primeira etapa na determinação de uma estratégia de controle da vibração de um transformador em operação é a aquisição de sinais de aceleração de pontos de uma malha previamente definida. Para definir a malha de pontos de medição de aceleração é necessário conhecer as características geométricas do transformador.

\subsubsection{Geometria do Transformador}

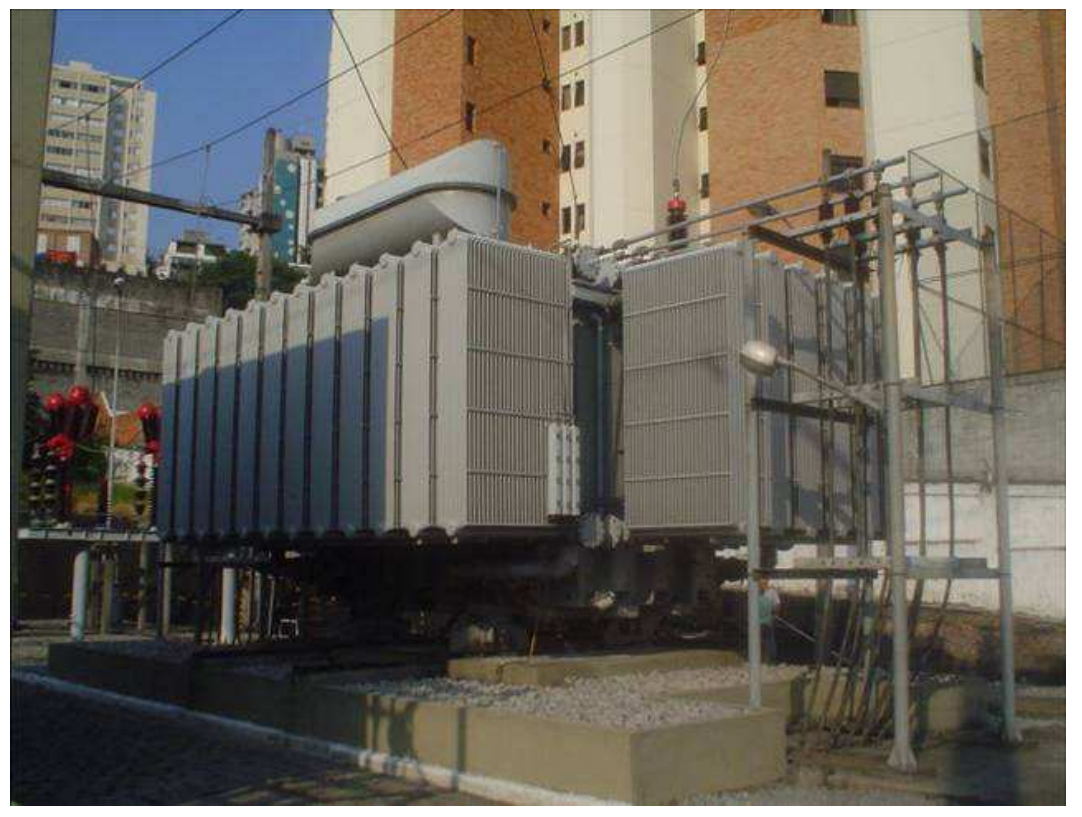

Figura 4.1: Transformador regulador de potência 30/40 MVA, 138-13,8/11,95 kV

\footnotetext{
${ }^{3}$ ver explicação na seção - 4.4
} 
O transformador de potência estudado é um dos dois transformadores localizados na Subestação Bela Aliança da Eletropaulo (Rua Natingui 97, Vila Madalena). A Fig. 4.1 mostra o transformador e a proximidade aos prédios residenciais, a distância até o prédio mais próximo é de $15 \mathrm{~m}$. Observa-se que com os gráficos apresentados na seção - 1.3.2 pode-se estimar o nível de ruído ao qual estão expostos os moradores vizinhos à Subestação. Este nível é aproximadamente de $60 \mathrm{~dB}(\mathrm{~A})$, que é superior ao nível máximo definido pela NBR 10151, 45 dB no período diurno.

As Figuras 4.2 e 4.3 mostram algumas das características geométricas do tanque do transformador, que foi desenhado a partir de medições realizadas em campo e a ajuda de uma ferramenta CAD para gerar a estrutura em 3D. O tanque está suportado por 4 apoios (rodas apoiadas no chão), a distância entre o piso de concreto e a placa base do tanque é de 0,475 m, o tanque é de forma retangular com largura, comprimento e altura de 2,5 m, 5,6 m, e 3,45 m respectivamente, as paredes do tanque tem uma espessura de $0,01 \mathrm{~m}$.

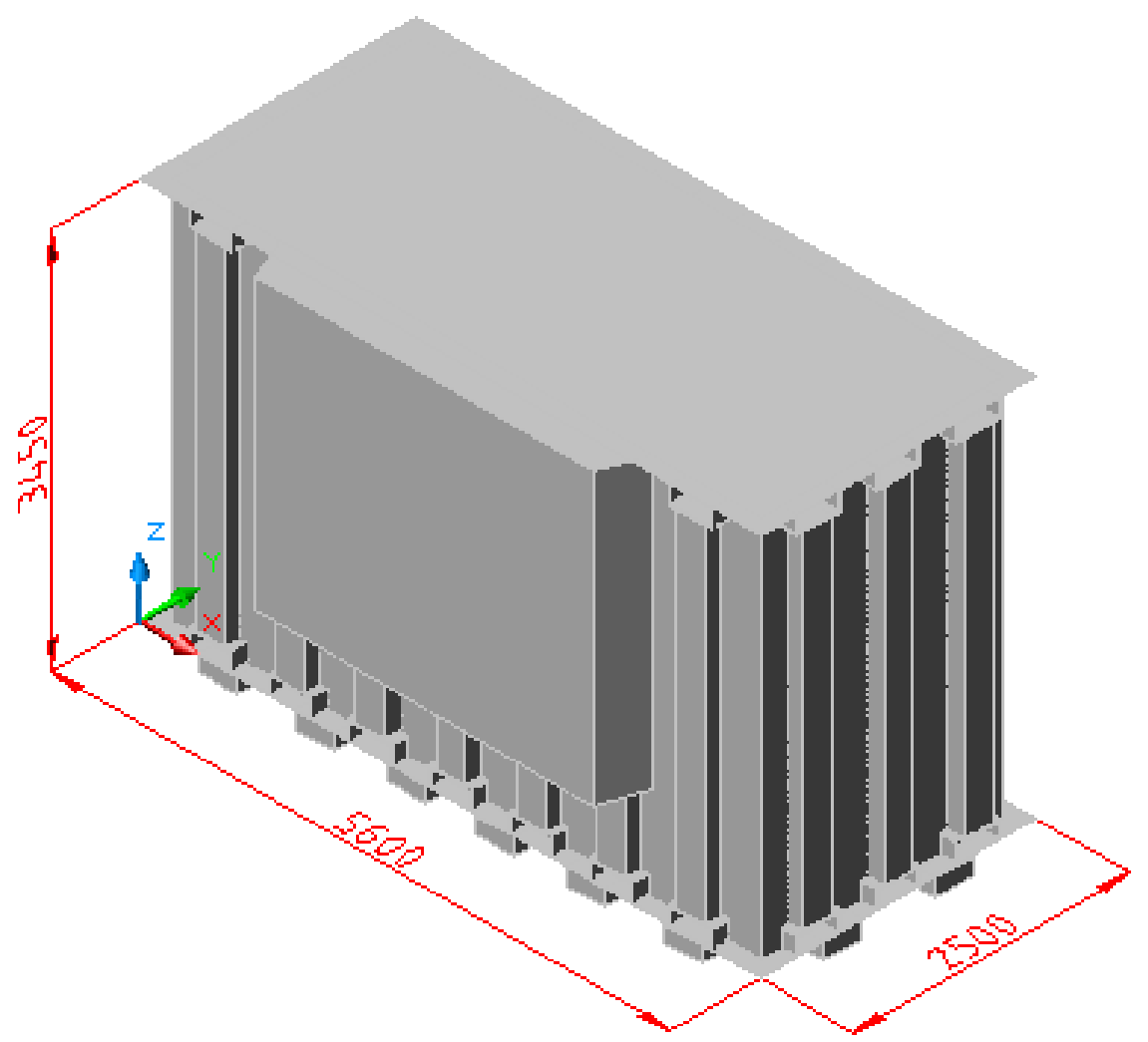

Figura 4.2: Geometria do tanque do transformador 


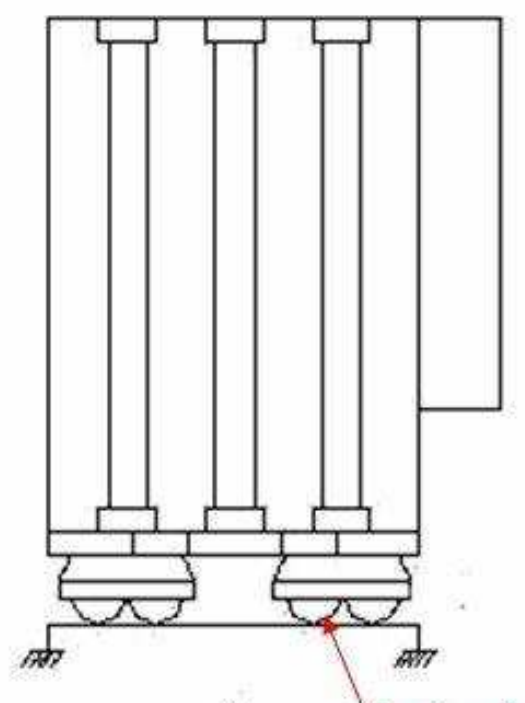

a)

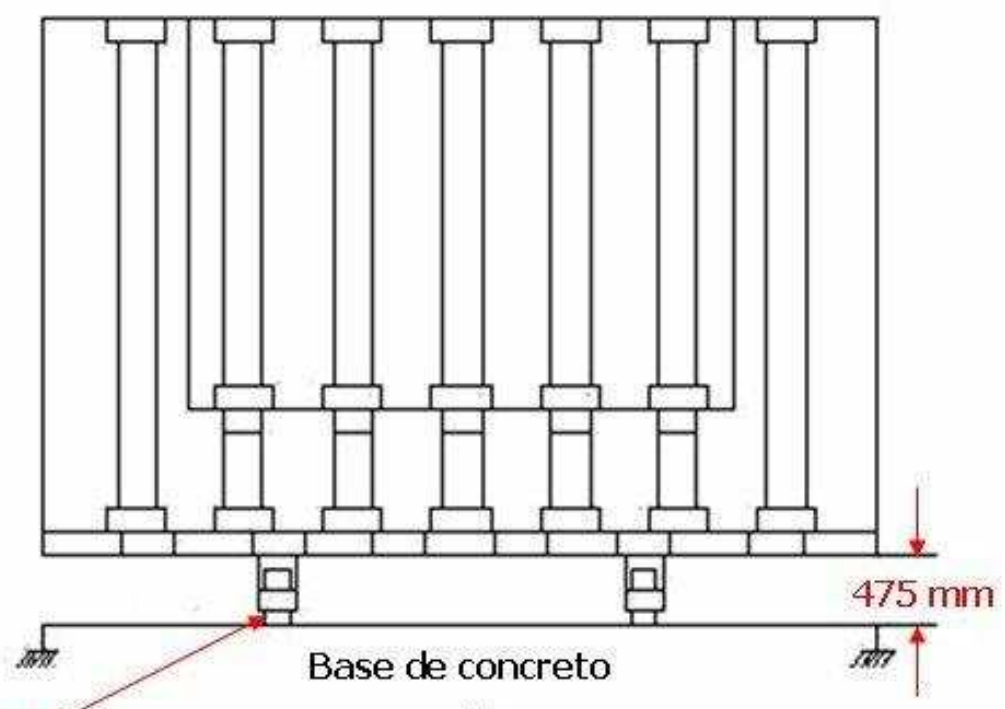

b)

Figura 4.3: a) Esquema da face frente à rua; b) Esquema da face frente aos prédios

\subsubsection{Aquisição de dados de vibração}

Para a aquisição de dados devem ser tomados em conta os seguintes parâmetros:

- Identificar cada face do tanque do transformador adotando nomes para cada uma delas, tendo como referência a localização do transformador dentro da subestação (ver Fig. 4.4);

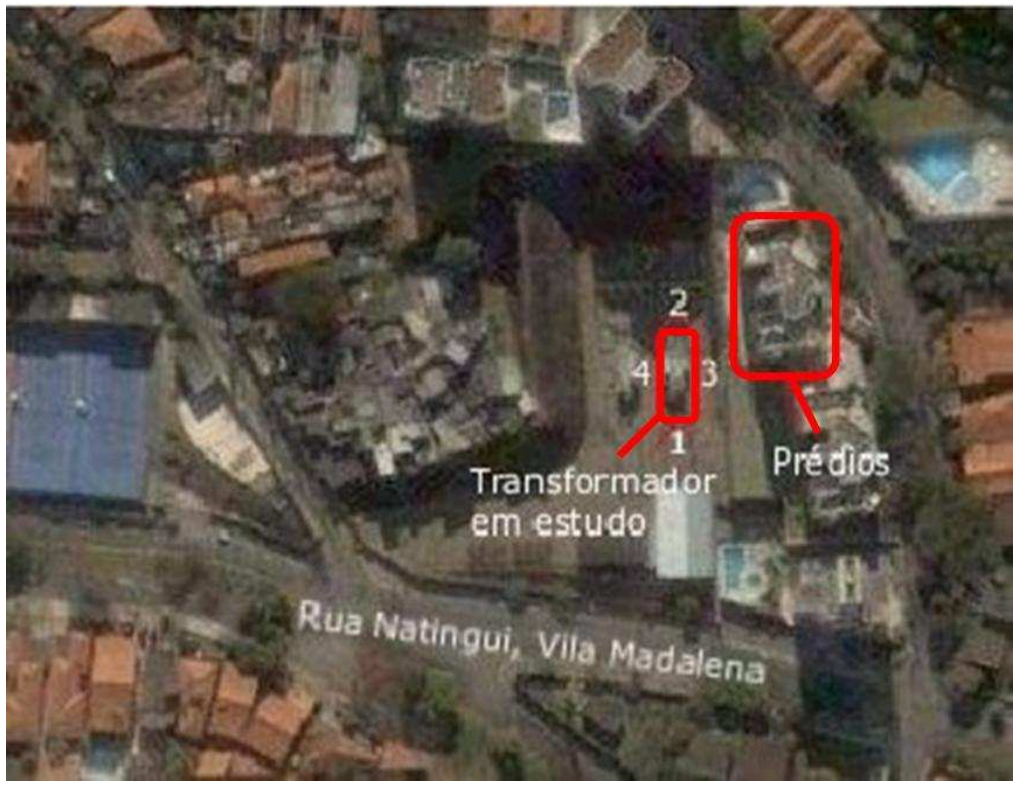

Figura 4.4: Localização da Subestação Bela Aliança 
Assim os nomes adotados foram:

1. face frente à rua (face do transformador próxima a rua Natingui, Vila Madalena);

2. face oposta à rua (face oposta à face frente à rua);

3. face frente aos prédios (face do transformador mais próxima aos prédios);

4. face oposta aos prédios (face oposta à face frente aos prédios);

5. base (face da placa base situada abaixo do tanque).

- Coletar sinais de vibração (aceleração) por etapas seguindo o contorno das faces do tanque do transformador. Estes sinais de aceleração devem ser coletados em vários pontos do tanque, assim como, nos subsistemas a ele fixados.

A coleta dos sinais de aceleração foram realizadas pela empresa $01 \mathrm{~dB}$-Brasil ${ }^{4}$ utili- $^{-}$ zando a técnica ODS, com o objetivo de obter informação sobre o comportamento dinâmico do transformador em operação. As medições foram coletadas utilizando 9 acelerômetros, tendo um acelerômetro fixo como referência, e os outros 8 acompanhando a propagação das vibrações no contorno do transformador, começando da base para cima (ver Fig. 4.5). Foram coletados em total 332 sinais de aceleração, 138 no tanque e 194 nos demais componentes

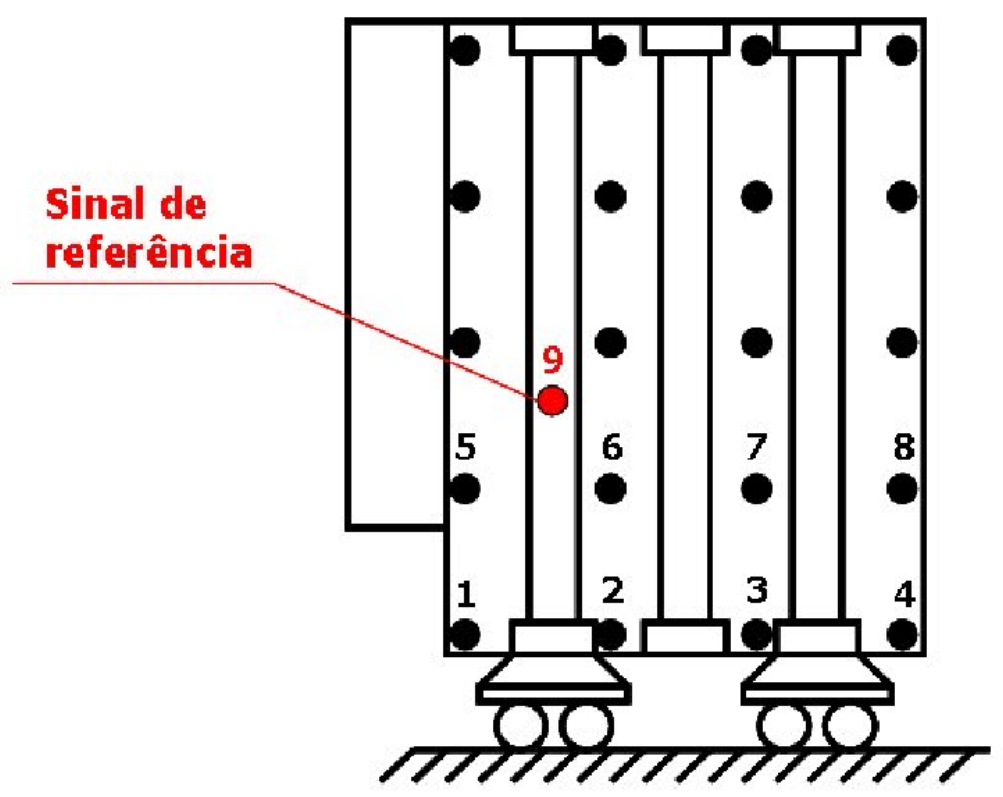

Figura 4.5: Representação da localização dos acelerômetros na face do transformador oposta à rua

\footnotetext{
${ }^{4}$ http://www.01db.com.br/
} 
- Para o tratamento dos sinais (aceleração) utilizaram-se os seguintes parâmetros:

1. Freqüência de amostragem: 12,8 kHz;

2. Número de pontos: 25602;

3. Filtros analógicos passa baixo: $10 \mathrm{kHz}$;

4. Todos os sinais foram digitalizados em Volts;

5. Sensibilidade do acelerômetro: $6\left(\frac{m V}{m s^{-2}}\right)$.

\subsection{Tratamento dos sinais de aceleração}

Os sinais de aceleração do tanque do transformador com base nos dados de ODS devem ser tratados e processados, para que o ruído inerente a procedimentos de medida sejam minimizados. Vários fatores podem falsear a informação: leakage, aliasing, falta de resolução na freqüência, drift dos amplificadores eletrônicos, etc.

A fim de evitar tais problemas, deve ser elaborada uma rotina para tratamento dos sinais tendo em conta alguns parâmetros ${ }^{5}$. As etapas de tratamento dos sinais são (ver Fig. 4.6)

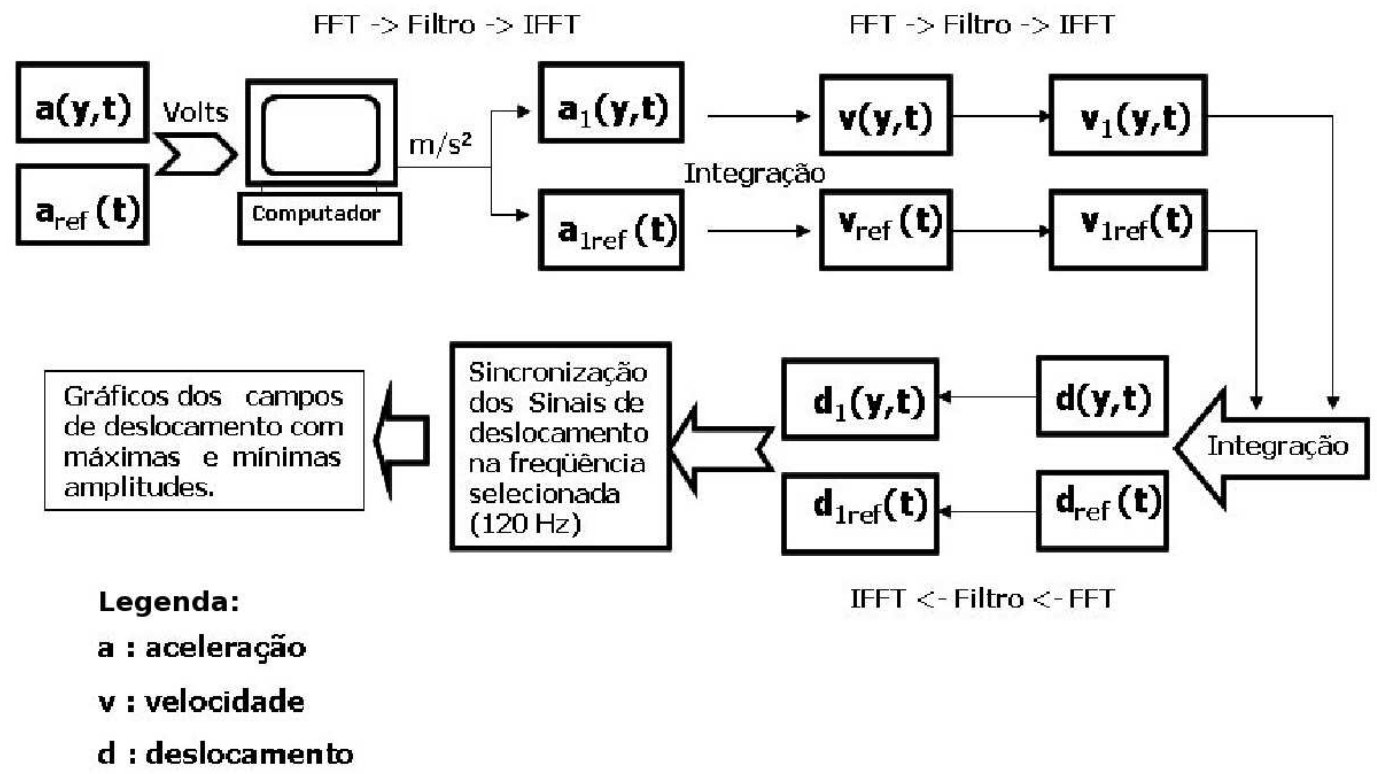

Figura 4.6: Esquema representativo do processamento dos sinais

- o sinal de aceleração deve ser dividido pela sensibilidade do acelerômetro;

\footnotetext{
${ }^{5}$ ver Apêndice - A.4
} 
- obtenção do sinal de aceleração em $\left(\mathrm{m} / \mathrm{s}^{2}\right)$;

- realizar FFT do sinal de aceleração;

- filtragem da FFT do sinal de aceleração em torno da freqüência selecionada, 120 $\mathrm{Hz}$;

- realizar IFFT para obter o sinal no tempo;

- integração do sinal de aceleração no tempo.

- obtenção do sinal de velocidade em $(\mathrm{m} / \mathrm{s})$.

- realizar FFT do sinal de velocidade.

- filtragem da FFT do sinal de velocidade em torno da freqüência selecionada, 120 $\mathrm{Hz}$;

- realizar IFFT para obter o sinal no tempo;

- integração do sinal de velocidade no tempo;

- obtenção do sinal de deslocamento em $(m)$;

- realizar FFT do sinal de deslocamento;

- filtragem da FFT do sinal de deslocamento em torno da freqüência selecionada, 120 $\mathrm{Hz}$;

- realizar IFFT do sinal de deslocamento;

- obtenção do sinal de deslocamento na freqüência selecionada.

Os sinais devem ser tratados utilizando um script de MATLAB para obter o deslocamento das 138 medições realizadas no tanque. Os sinais são cíclicos. O período dos sinais deve ser calculado. Para obter uma relação entre a amplitude e fase dos sinais de deslocamento, consideram-se todos estes a partir do instante em que o sinal de referência apresenta amplitude nula e derivada positiva.

Os sinais de deslocamento no espaço devem ser utilizados para gráficos que representem os deslocamentos máximos e mínimos de cada face do tanque. 


\subsection{Modelagem via Método dos Elementos Finitos}

Como mencionado na seção 1.3.1, uma das técnicas utilizadas para diminuir a vibração e o ruído acústico emitido por um transformador de potência é a instalação de absorvedores dinâmicos fixados ao tanque, que sintonizados na freqüência de excitação absorvam parte da energia da vibração de forma que não se acople com o ar. Nesta etapa deve ser estabelecido através do método dos elementos finitos (MEF) um modelo que represente o tanque do transformador com ADVs incorporados para simulações computacionais. O MEF permite discretizar um meio contínuo em pequenos elementos. A equação diferencial parcial que descreve a estrutura pode ser descrita através de um conjunto de equações diferenciais ordinárias.

\subsubsection{Modelo do Tanque}

A seguir apresentam-se os passos necessários para o desenvolvimento do modelo construído;

- para simular as vibrações da superfície do tanque deve ser desenvolvido um modelo numérico de elementos finitos contendo as dimensões, características geométricas e estruturais do transformador;

- construir uma malha do tanque contendo nós nos pontos onde foram feitas as medições de aceleração;

- fixar os nós que representam os 4 apoios do transformador sobre a superfície de concreto;

- impor forças nos nós onde foram feitas as medições de aceleração com forças senoidais de $120 \mathrm{~Hz}$ de amplitude proporcional ao deslocamento medido;

- a intensidade do vetor de forças deve ser tal que o máximo deslocamento medido seja igual ao máximo deslocamento calculado;

- construir a malha do ADV contendo um nó solidário ao nó da malha do tanque que apresentar maior deslocamento.

- simular o modelo do tanque com ADVs incorporados e determinar o novo nó com maior deslocamento e a redução na potência média de deslocamento da face do tanque; 
- repetir os últimos dois ítens para incluir mais ADVs.

Para processar o modelo via método dos elementos finitos utilizar o processador de Elementos Finitos CalculiX ${ }^{6}$, que permite calcular os deslocamentos nodais. Para o desenvolvimento das malhas foram utilizados elementos hexaédricos e o pré-processador de Elementos Finitos GraphiX, cada elemento gerado consta de 20 nós (C3D20) como se mostra na Fig. 4.7.

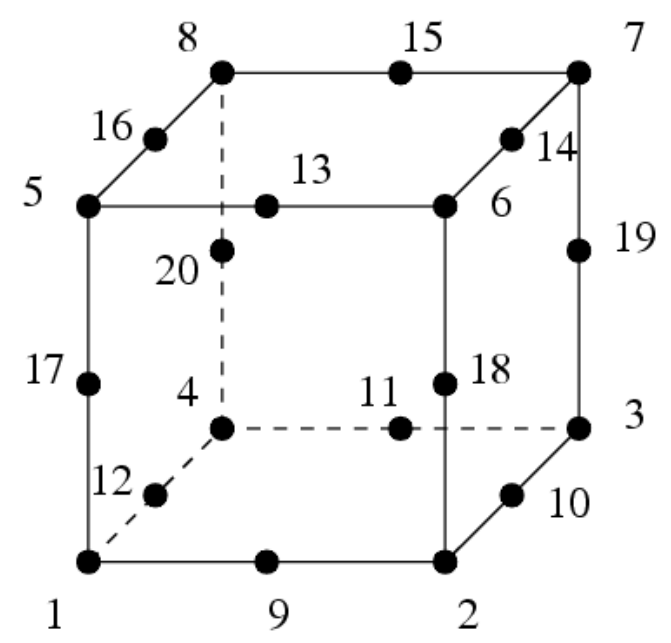

Figura 4.7: Elemento hexaédrico C3D20 (20 nós)

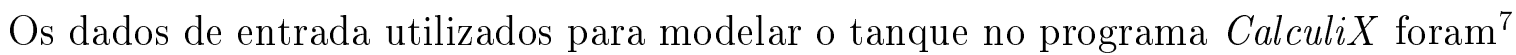

- coordenadas e número de nós gerados;

- número de elementos;

- conectividade entre elementos;

- tipo de elemento utilizado (C3d20);

- características do material (Aço);

- módulo de elasticidade $\left(210 \times 10^{9} \mathrm{~N} / \mathrm{m}^{2}\right)$;

- densidade $\left(7800 \mathrm{~kg} / \mathrm{m}^{3}\right)$;

- coeficiente de Poisson (0.3);

\footnotetext{
${ }^{6}$ http://www.calculix.de/ - ver Apêndice - A.5

${ }^{7}$ ver arquivo de entrada do CalculiX no Apêndice - D
} 
- forças proporcionais aos deslocamentos medidos.

A malha do tanque mostrada na Fig. 4.8 consta de 6217 nós e 868 elementos as dimensões foram mostradas na seção 4.1.

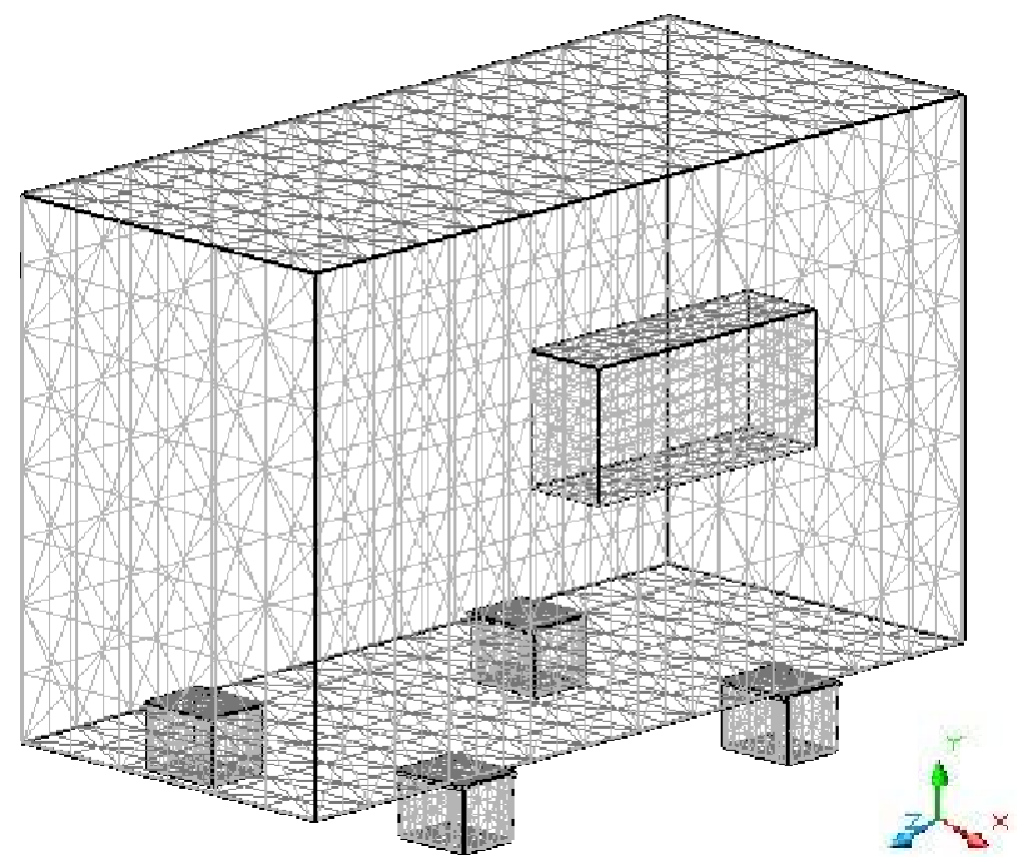

Figura 4.8: Malha do tanque do transformador

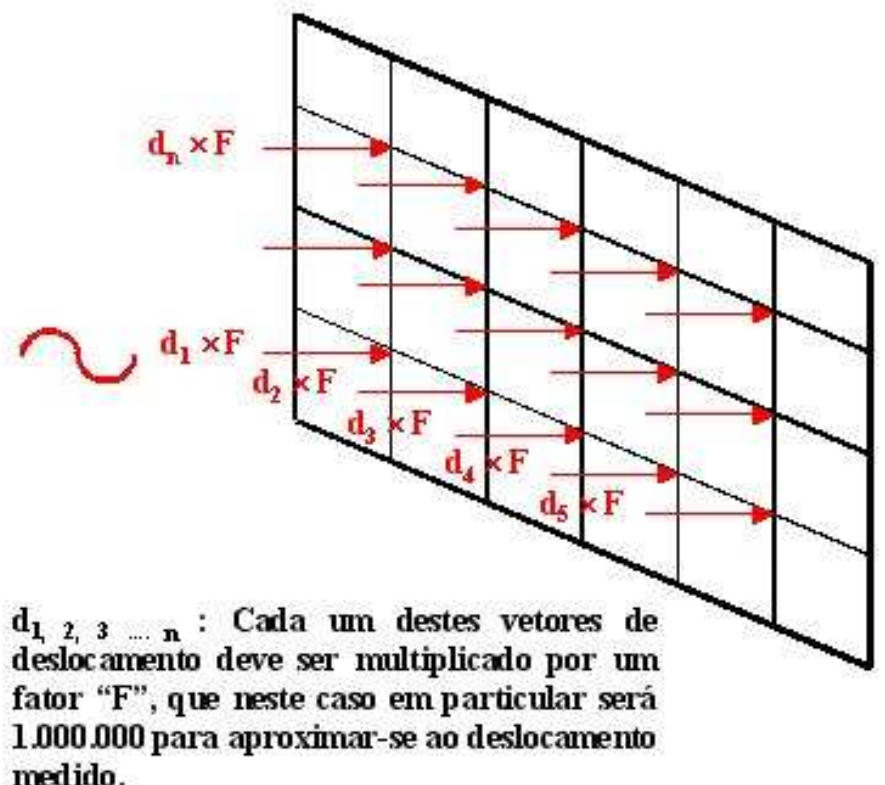

Figura 4.9: Esquema do carregamento de forças de uma face do modelo do tanque 
Já que desconhece-se como ocorre de fato o carregamento estrutural das forças que geram a vibração assim como o ruído acústico emitido pelo tanque do transformador, no modelo da Fig. 4.8 este carregamento de forças será estimado utilizando os 109 pontos de cada um dos deslocamentos obtidos pelo processamento dos sinais multiplicado por um fator que irá variando até conseguir através do programa CalculiX que as faces do tanque gerem deslocamentos próximos ao deslocamento medido. A Fig. 4.9 representa esquematicamente como seria o carregamento das forças para uma das faces do transformador (Observe-se que o fator multiplicativo dos deslocamentos foi de $10^{6}$ ).

\subsubsection{Modelo de um ADV}

Para a construção das malhas dos ADVs utilizaram-se 4 modelos que representam ADVs com massas de 5, 10, 20,30, 40 e $80 \mathrm{~kg}$. A Fig. 4.10 mostra as características dimensionais dos ADVs. Para obter modelos de ADVs com massas diferentes a dimensão $\boldsymbol{x}$ da Fig. 4.10 deve ser incrementada. Assim, os valores da dimensão $\boldsymbol{x}$ neste caso em particular variam de $0,1 \mathrm{~m}$ até $1,4 \mathrm{~m}$ para massas na faixa de 5 a $80 \mathrm{~kg}$. Os valores da dimensão $\boldsymbol{y}$ e $\boldsymbol{z}$ permanecem constantes e iguais a $0.08 \mathrm{~m}$. As malhas dos ADVs constam de 67 nós e 5 elementos. A malha de um modelo de ADV é mostrada na Fig. 4.11.

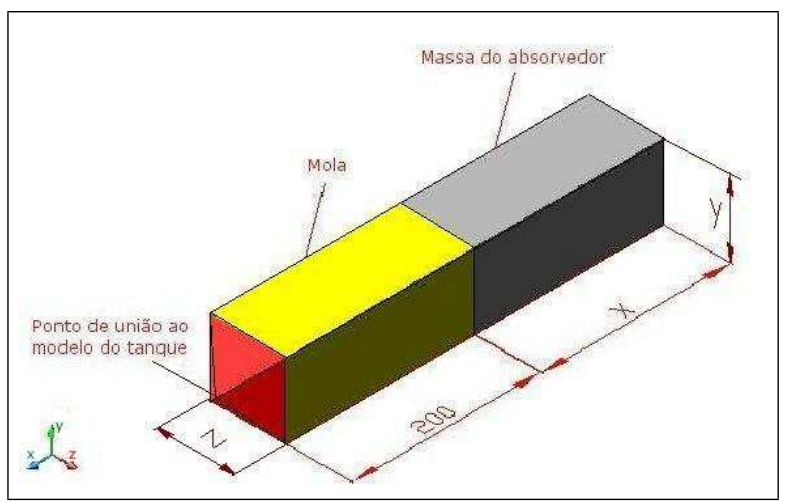

Figura 4.10: Modelo do ADV

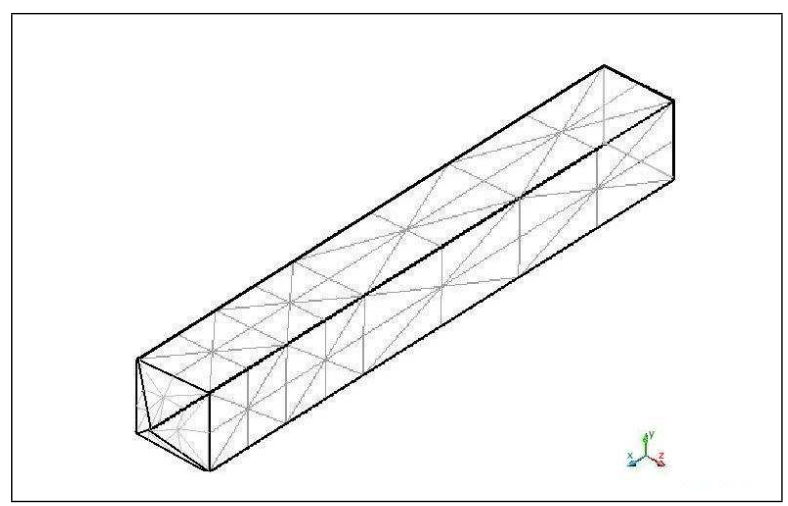

Figura 4.11: Malha do ADV

Já que CalculiX não contem o elemento tipo mola optou-se por representar a mola como uma viga (ver Fig. 4.10), onde o coeficiente de rigidez será obtido no CalculiX modificando o módulo de elasticidade desta viga para cada um dos 6 tipos de ADVs utilizados.

O cone em vermelho da Fig. 4.10 representa o elemento que deve ser unido aos nós do tanque onde foram realizadas as medidas de aceleração (ver Fig. 4.12); este elemento 
de união assim como o elemento que representa a massa dos ADVs devem ter as mesmas características do elemento utilizado para o tanque (material, módulo de elasticidade, densidade, entre outros).

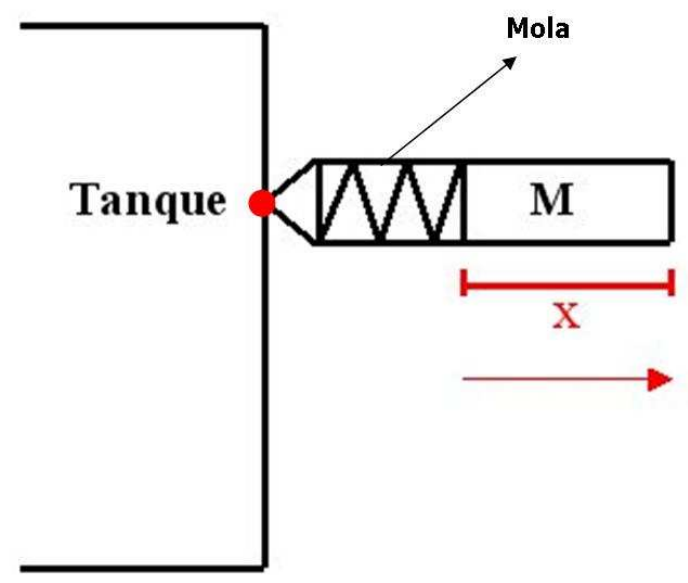

Figura 4.12: Esquema representativo de união de um ADV ao tanque

Para sintonizar os ADVs em uma freqüência pouco acima de $120 \mathrm{~Hz}$ realizou-se no CalculiX o análise modal de cada modelo, fixando alguns nós em duas direções, para que o modelo dos ADVs só consigam deslocar-se na direção perpendicular à face onde está fixado. O módulo de elasticidade dos materiais que representam as molas de cada ADVs varia dependendo da massa utilizada. O módulo de elasticidade da viga que representa a mola para:

- ADVs com massa de $5 \mathrm{~kg}\left(120 \times 10^{6} \mathrm{~N} / \mathrm{m}^{2}\right)$;

- ADVs com massa de $10 \mathrm{~kg}\left(188,23 \times 10^{6} \mathrm{~N} / \mathrm{m}^{2}\right)$;

- ADVs com massa de $20 \mathrm{~kg}\left(311,47 \times 10^{6} \mathrm{~N} / \mathrm{m}^{2}\right)$;

- ADVs com massa de $30 \mathrm{~kg}\left(436,12 \times 10^{6} \mathrm{~N} / \mathrm{m}^{2}\right)$;

- ADVs com massa de $40 \mathrm{~kg}\left(561,37 \times 10^{6} \mathrm{~N} / \mathrm{m}^{2}\right)$;

- ADVs com massa de $80 \mathrm{~kg}\left(1061,21 \times 10^{6} \mathrm{~N} / \mathrm{m}^{2}\right)$;

\subsection{Redução da intensidade de ruído acústico}

Para calcular a redução de ruído acústico emitido pelo transformador, segundo (BIES; HANSEN, 1996) explicam que a potência sonora, irradiada pela superfície de uma má- 
quina pode ser calculada avaliando a energia da superfície usando a velocidade média ao quadrado e que na proximidade de uma placa plana a relação entre a vibração e a velocidade do ar na mesma freqüência, obedece à Eq. 4.1:

$$
\frac{a^{2}}{a_{r e f}^{2}}=\frac{v^{2}}{v_{r e f}^{2}}=\frac{d^{2}}{d_{r e f}^{2}} \cong \frac{v^{2}}{v_{r e f}^{2}}
$$

onde $a, v, d$ denotam a aceleração, velocidade e deslocamento médio de cada uma das superfícies do transformador; $v$ denota os valores da velocidade média do ar e o sub-escrito ref denota uma condição de referência em relação a uma condição nova.

(BIES; HANSEN, 1996) mencionam também que a manifestação do som pode ser avaliada com a medição do nível de velocidade $L_{v}$ definido como:

$$
L_{v}=10 \times \log _{10}\left[\frac{v^{2}}{v_{r e f}^{2}}\right]
$$

Já que pela Eq. $4.1 \frac{d^{2}}{d_{r e f}^{2}} \cong \frac{v^{2}}{v_{r e f}^{2}}$, define-se aqui potência média de deslocamento pela Eq. 4.3.

$$
P=\frac{1}{n}\left(\sum_{i=0}^{n} d_{i}^{2}\right)
$$

onde $n$ denota o número de nós da malha de elementos finitos em uma face, $d_{i}$ denota o deslocamento nodal do i-ésimo nó da malha de elementos finitos no instante de maior amplitude de movimento e $P$ é a potência média de deslocamento nodal.

Portanto a Eq. 4.2 pode ser expressada como:

$$
L_{p}=10 \times \log _{10}\left[\frac{P}{P_{r e f}}\right]
$$

onde $P_{\text {ref }}$ denota a potência média de deslocamento quando cada superfície do transformador encontra-se sem nenhum ADVs incluído e $P$ denota a potência média de deslocamento enquanto os ADVs são incluídos. Os dados obtidos devem ser utilizados para mostrar gráficos de cada superfície do transformador mostrando a relação entre a porcentagem de redução da potência média de deslocamento e a redução da intensidade do ruído acústico $(\mathrm{dB})$. 


\section{RESULTADOS}

Neste capítulo apresentam-se os resultados das simulações realizadas. As simulações testam a hipótese de que absorvedores são capazes de reduzir a vibração do tanque e tem a intenção de estimar a redução do ruído acústico que absorvedores dinâmicos podem causar.

\subsection{Análise do tratamento dos sinais de aceleração}

Após realizadas as medições, a empresa 01dB-Brasil forneceu animações em 3D mostrando o deslocamento do transformador em determinadas freqüências (120, 241 e 359 $\mathrm{Hz}$ ), as quais mostraram que a freqüência com maior amplitude é $120 \mathrm{~Hz}$. A literatura especializada informa que a utilização de absorvedores dinâmicos é recomendável neste transformador.

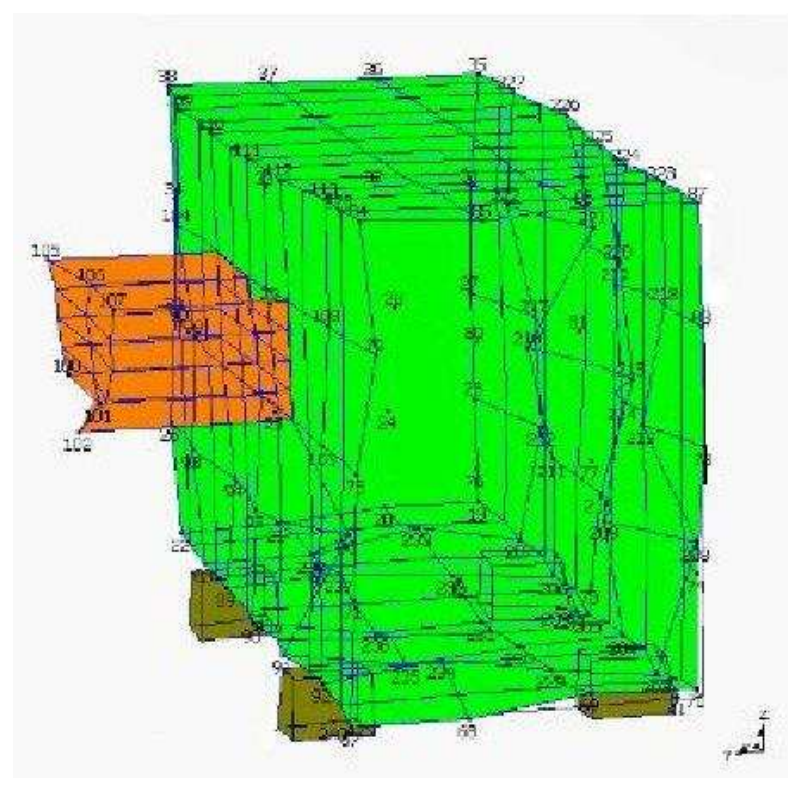

Figura 5.1: Modelo geométrico mostrando o deslocamento da superfície do tanque 01dB-Brasil 
Com os sinais de aceleração coletados a $01 d B$-Brasil calculou sinais de correlação cruzada com o sinal de referência. A Fig. 5.2 mostra que a freqüência com maior potência ocorre em torno de $120 \mathrm{~Hz}$, sendo a potência nesta freqüência de 10 a 100 vezes maior quando comparada aos outros picos apresentados.

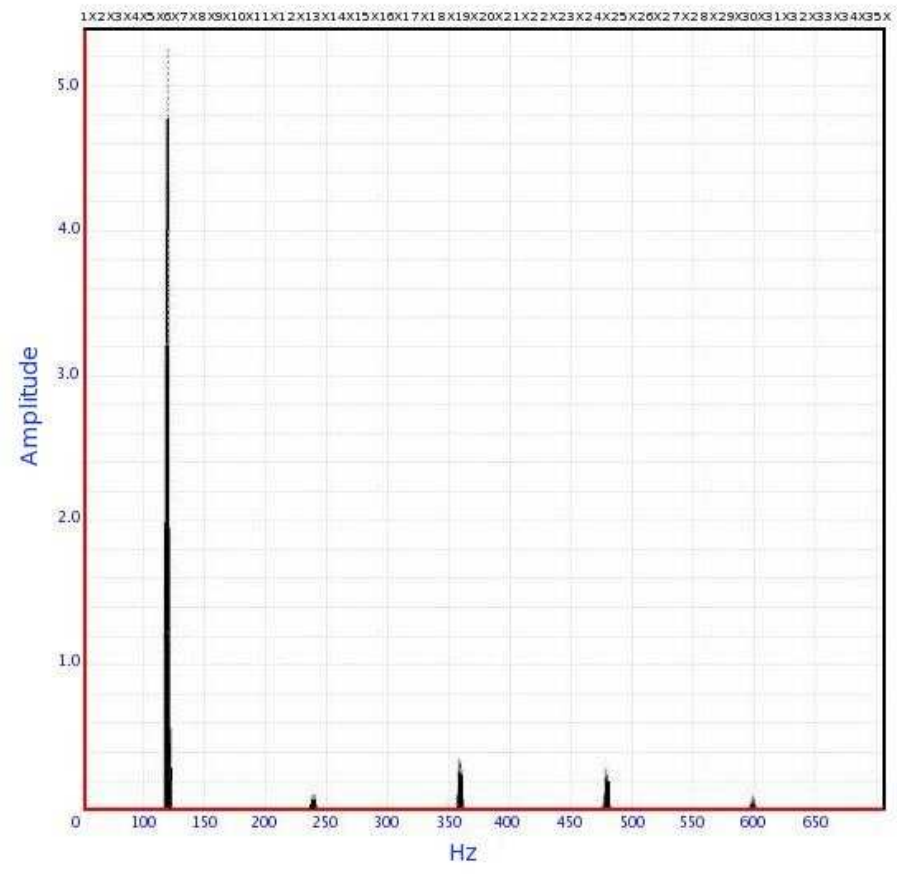

Figura 5.2: Espectros de freqüência da correlação cruzada

A Fig. 5.1, fornecida pela empresa $01 \mathrm{~dB}$-Brasil, representa deslocamentos de cada ponto medido no contorno do tanque, na freqüência de $120 \mathrm{~Hz}$. Observa-se que 3 dos apoios que suportam o transformador giram em torno de um apoio que permanece fixo, ver Fig. 5.3. Portanto, há um movimento de corpo rígido, de rotação, cujo eixo de rotação é vertical e passa pelo apoio fixo.

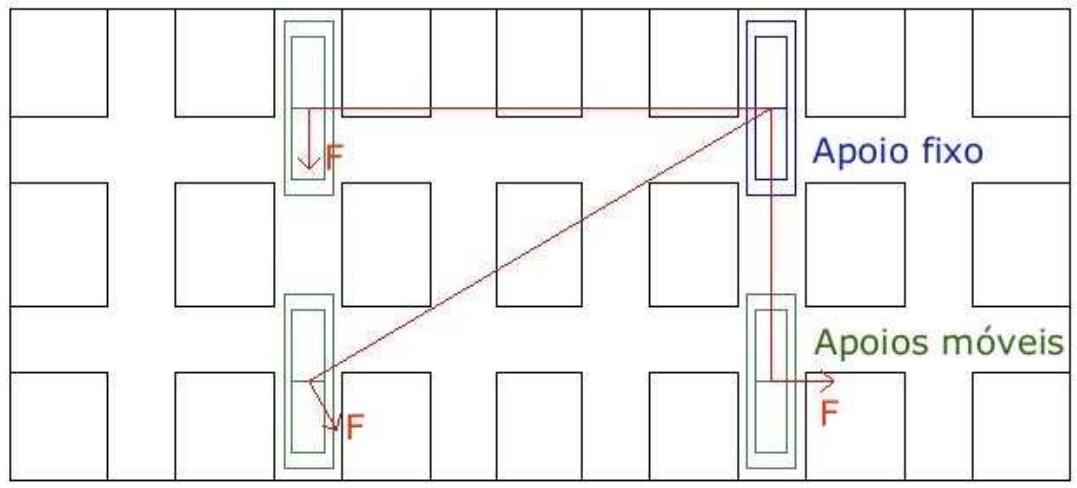

Figura 5.3: Face da placa base situada abaixo do tanque 
Os dados brutos de aceleração medidos pela 01dB-Brasil foram integrados, neste trabalho, duas vezes de acordo com o procedimento descrito na Metodologia ${ }^{1}$. Foram obtidos gráficos de deslocamento para as cinco faces do tanque. Os gráficos de deslocamento obtidos pela metodologia deste trabalho são mais suaves que os obtidos pela 01dB-Brasil. A informação que foi retirada, por filtro passa banda, do sinal original refere-se a freqüências fora da vizinhança dos $120 \mathrm{~Hz}$, e portanto é um método coerente e com a informação procurada, o campo de deslocamento em $120 \mathrm{~Hz}$. Qualitativamente, o procedimento de integração empregado neste trabalho parece mais adequado, porque gera gráficos de deslocamento mais suaves.

Com o objetivo de encontrar as regiões de maior deslocamento periódico das superfícies do tanque, os vetores de deslocamento, que tem período de 109 intervalos de amostragem, foram introduzidos em malhas que representam cada uma das 5 faces do tanque. Para isso utilizou-se um script de MATLAB. Resultaram dez gráficos de contorno coloridos que representam os campos de deslocamento nas cinco faces.

\subsection{Análise das faces do tanque do Transformador}

Nos seguintes gráficos serão representados os deslocamentos das 5 faces do tanque do transformador . Para cada face são apresentados 2 gráficos. No primeiro deles está representado o campo de deslocamento com a máxima amplitude, positiva, e no segundo está representado o campo de deslocamento com a mínima amplitude, negativa.

\subsubsection{Análise da face frente aos prédios}

Na face frente aos prédios os campos de maior deslocamento são apresentados no quadrante inferior direito, ver Fig. 5.4 e Fig. 5.5. O maior deslocamento positivo tem uma amplitude de $1,30 \times 10^{-5} \mathrm{~m}$, e o menor deslocamento negativo uma amplitude de $-1,12 \times 10^{-5} \mathrm{~m}$.

\footnotetext{
${ }^{1}$ ver o script de Matlab no Apêndice -C
} 


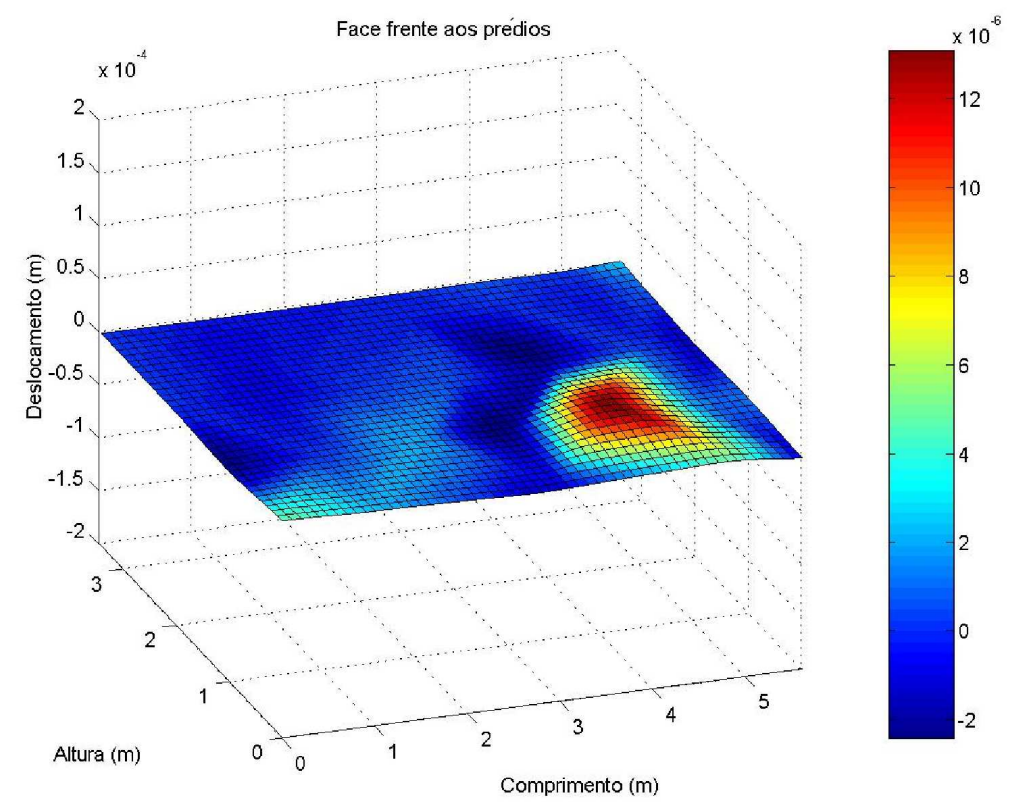

Figura 5.4: Face frente aos prédios máxima amplitude positiva

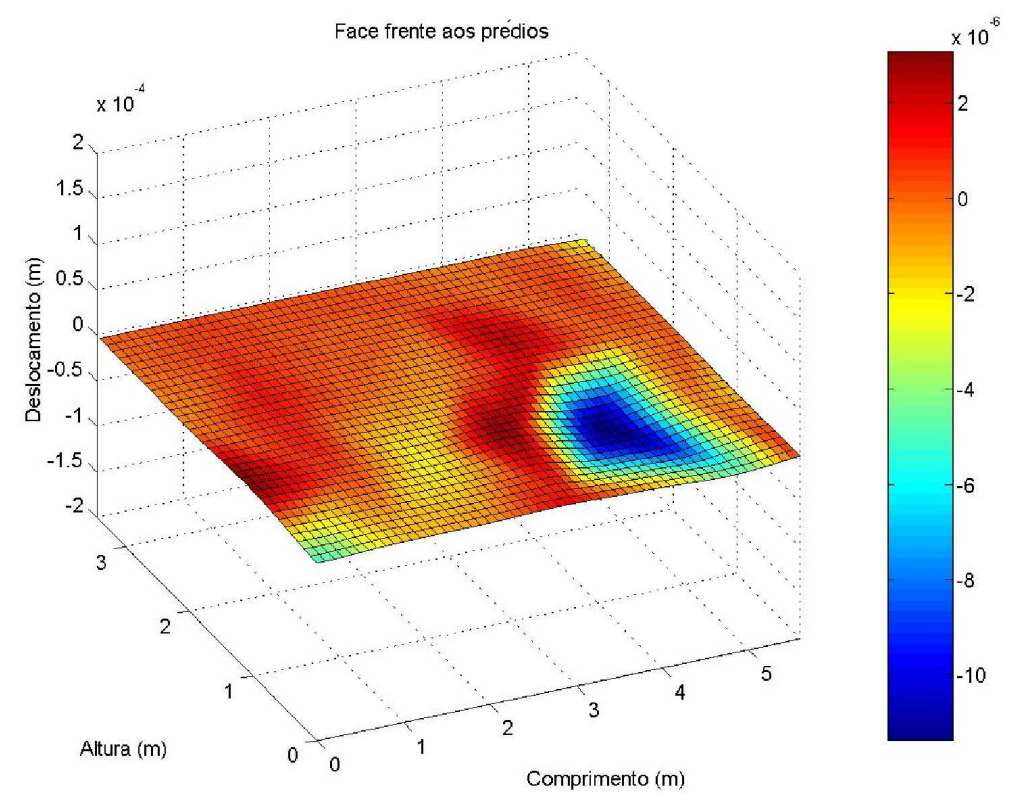

Figura 5.5: Face frente aos prédios mínima amplitude negativa

\subsubsection{Análise da face oposta aos prédios}

Na face oposta aos prédios o campo de maior deslocamento ocorre no quadrante superior direito, ver Fig. 5.6 e Fig. 5.7. O maior deslocamento positivo tem uma amplitude de $1,38 \times 10^{-5} \mathrm{~m}$, e o menor deslocamento negativo uma amplitude de $-1,36 \times 10^{-5} \mathrm{~m}$. 


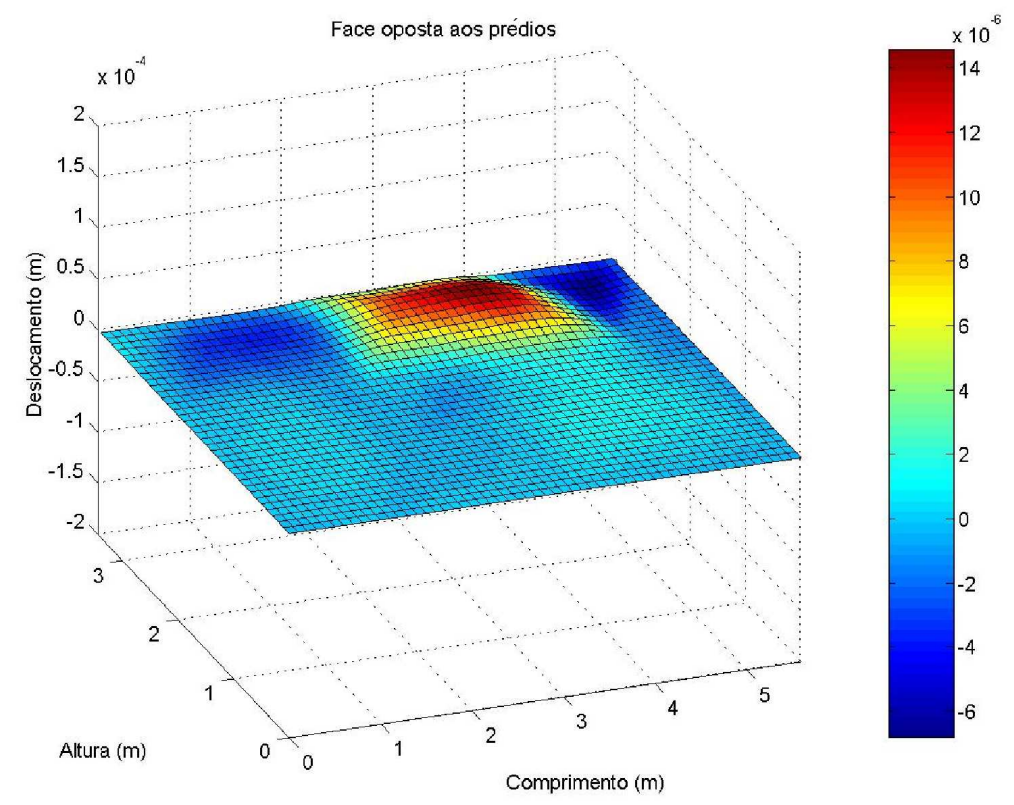

Figura 5.6: Face oposta aos prédios máxima amplitude positiva

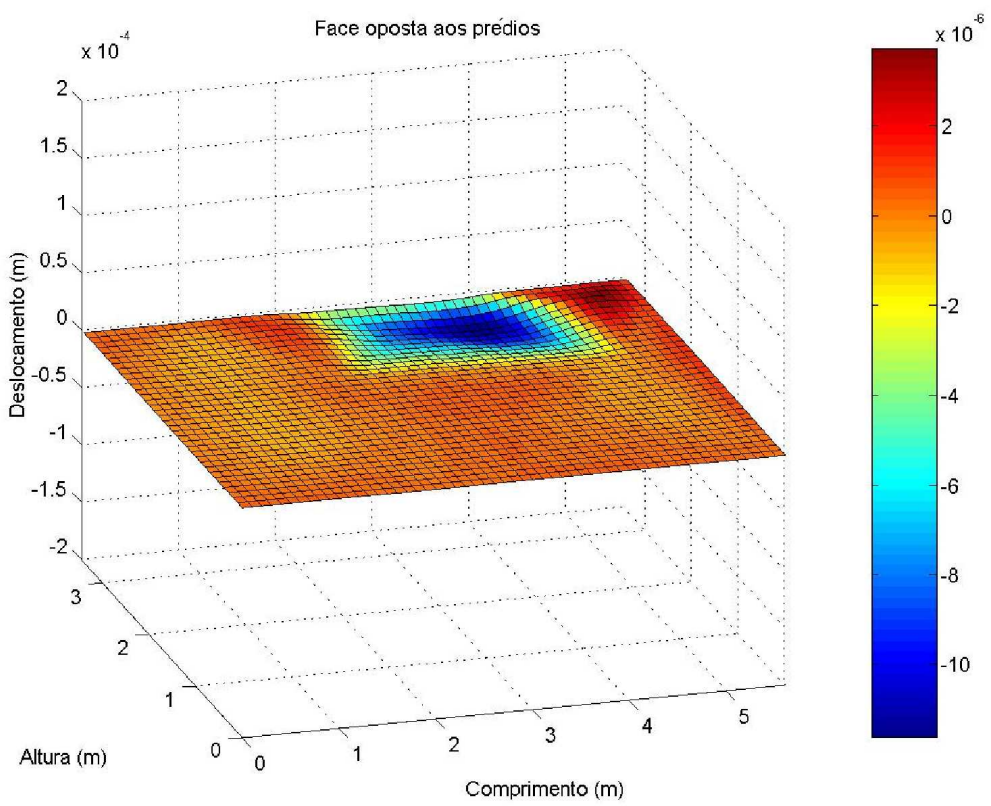

Figura 5.7: Face oposta aos prédios mínima amplitude negativa

\subsubsection{Análise da face frente à rua}

$\mathrm{Na}$ face frente à rua o campo de maior deslocamento ocorre no quadrante superior esquerdo, ver Fig. 5.8 e Fig. 5.9. O maior deslocamento positivo tem uma amplitude de $2,28 \times 10^{-5} \mathrm{~m}$, e o menor deslocamento negativo uma amplitude de $-2,98 \times 10^{-5} \mathrm{~m}$. 


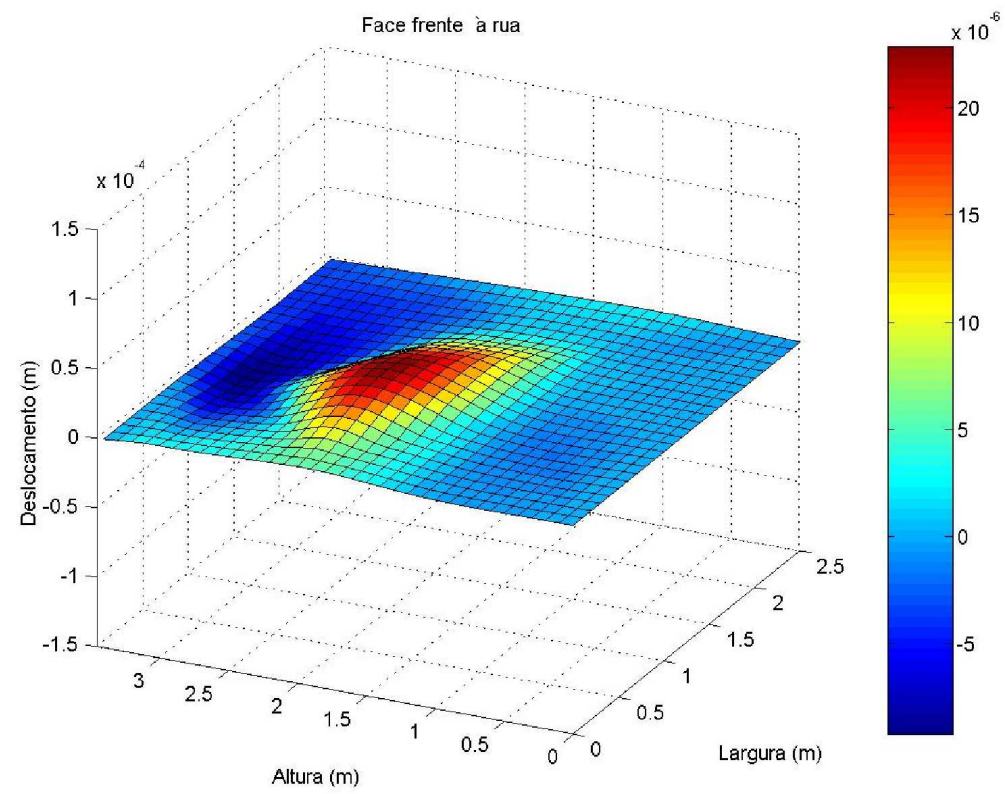

Figura 5.8: Face frente à rua máxima amplitude positiva

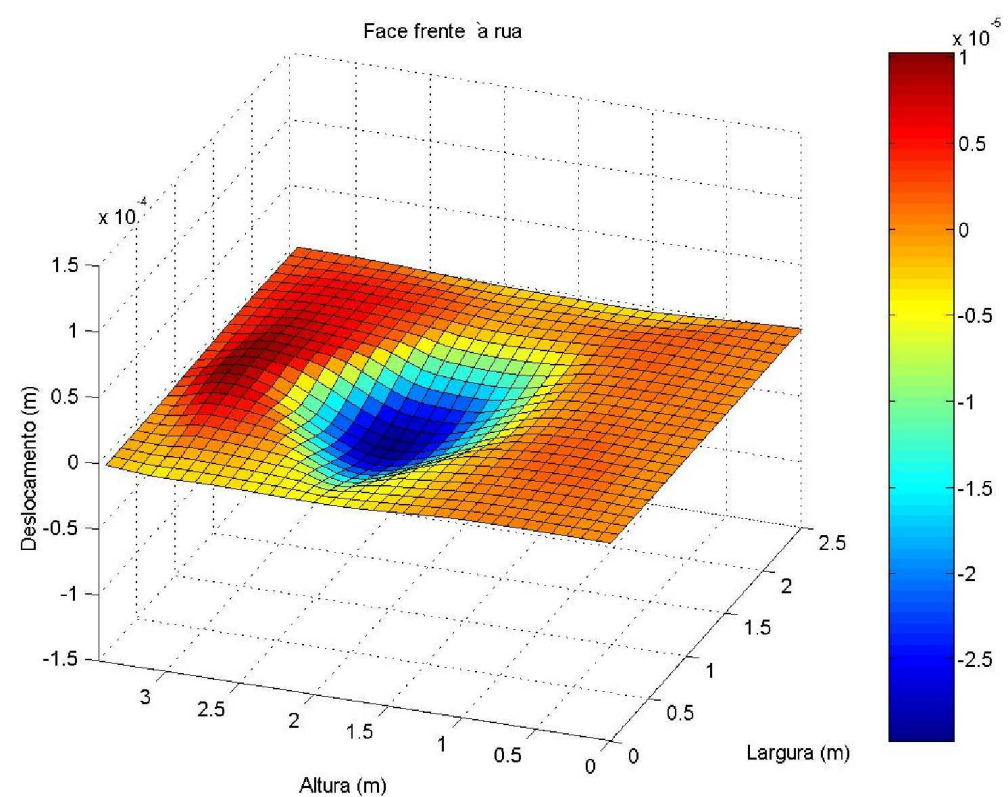

Figura 5.9: Face frente à rua mínima amplitude negativa

\subsubsection{Análise da face oposta à rua}

Na face oposta à rua o campo de maior deslocamento ocorre no quadrante superior esquerdo, ver Fig. 5.10 e Fig. 5.11. O maior deslocamento positivo tem uma amplitude de $4,38 \times 10^{-6} \mathrm{~m}$, e o menor deslocamento negativo uma amplitude de $-4,17 \times 10^{-6} \mathrm{~m}$. 


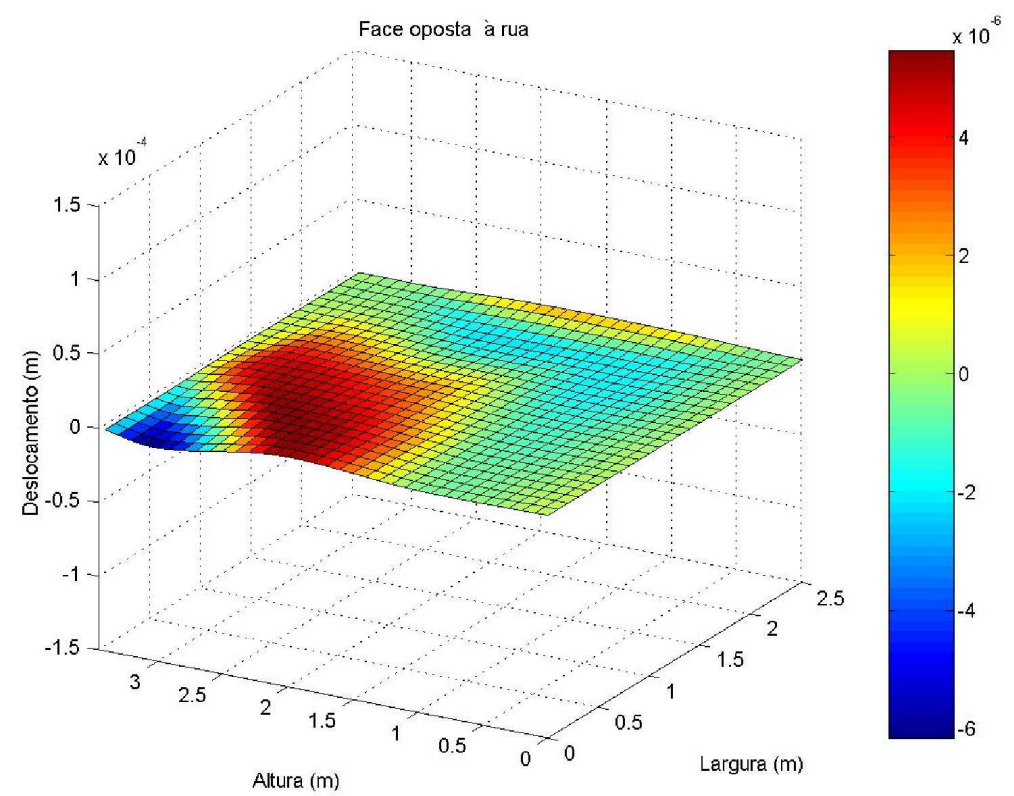

Figura 5.10: Face oposta à rua máxima amplitude positiva

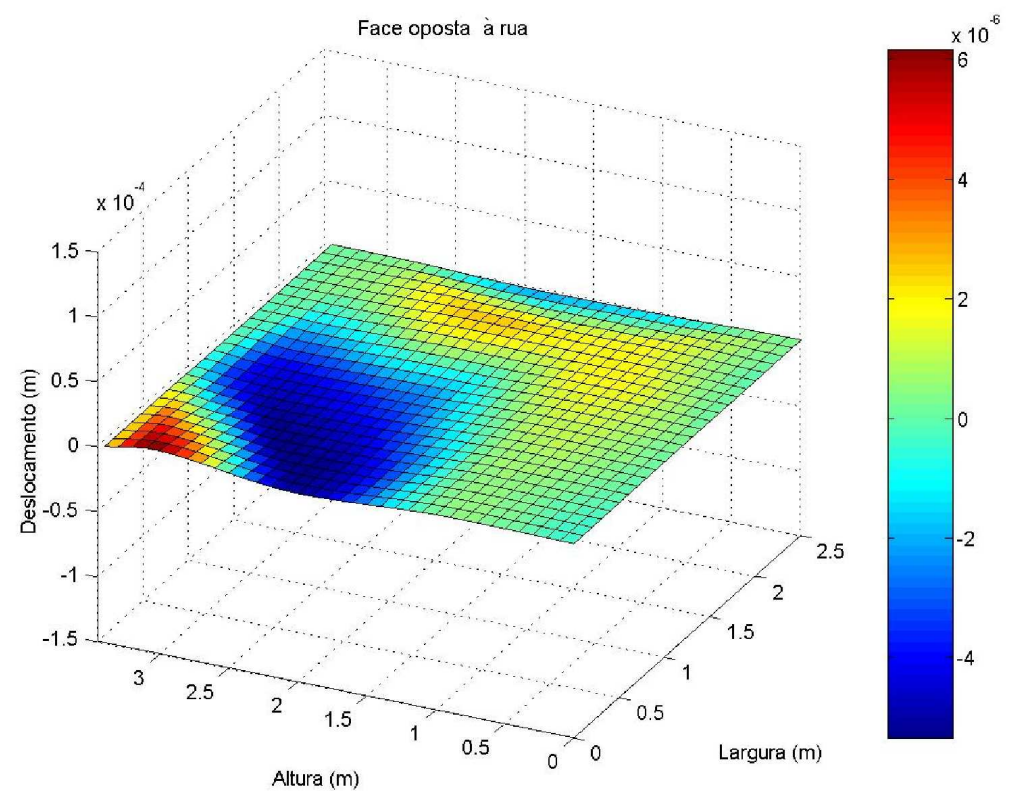

Figura 5.11: Face oposta à rua mínima amplitude negativa

\subsubsection{Análise da placa base}

Na placa base o campo de maior deslocamento ocorre no quadrante oposto à roda de apoio que permaneceu fixa, ver Fig. 5.12, Fig. 5.13 e seção 5.1, onde o maior deslocamento positivo tem uma amplitude de $1,63 \times 10^{-5} \mathrm{~m}$, e o menor deslocamento negativo uma 
amplitude de $-1,54 \times 10^{-5} \mathrm{~m}$.

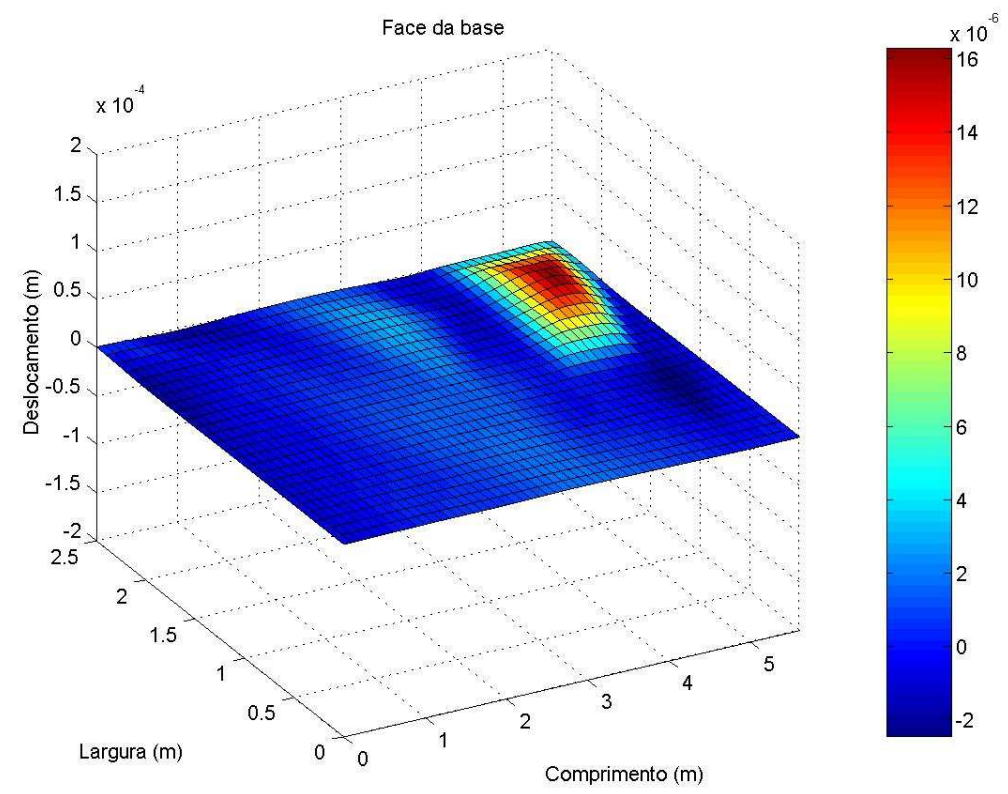

Figura 5.12: Face da placa base máxima amplitude positiva

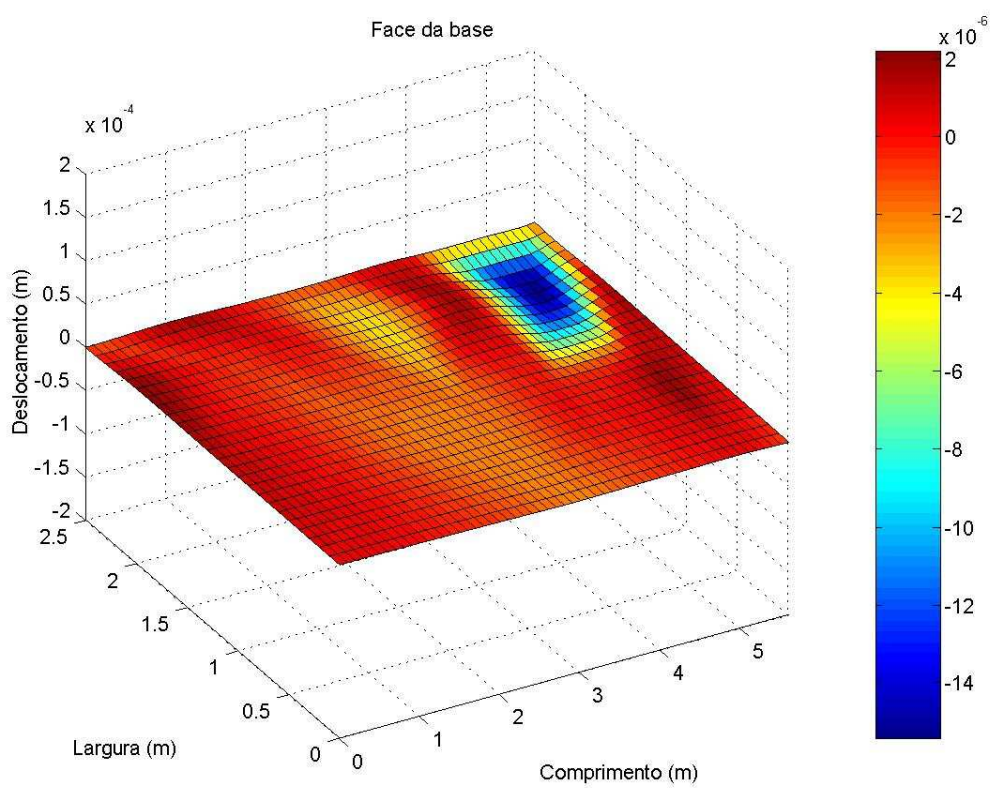

Figura 5.13: Face da placa base mínima amplitude negativa

O maior deslocamento ocorre na face frente à rua. Os gráficos mostram que as ondas são estacionárias e costumam ter dois lóbulos em oposição de fase. O comprimento desta onda estacionária varia de face para face. Na face frente aos prédios o comprimento dos 
dois lóbulos é de 3 metros. Na face oposta aos prédios o comprimento dos dois lóbulos é de 3,0 m. Na face frente à rua o comprimento dos dois lóbulos é de $1.5 \mathrm{~m}$. Na face oposta à rua o comprimento dos dois lóbulos é de 1,7 m.

A partir dos gráficos de deslocamentos das faces do transformador foram determinados os pontos de fixação dos primeiros cinco ADVs. Com o objetivo de determinar as posições e a quantidade de absorvedores dinâmicos mais efetiva, descrevem-se nas seções seguintes as simulações numéricas de modelos estruturais de cada face carregadas por forças senoidais proporcionais ao deslocamento de cada face.

\subsection{Análise do modelo via MEF}

Nesta seção serão analisadas as 4 faces do tanque do transformador, modeladas via MEF, quanto ao seu comportamento dinâmico, a medida que ADVs são fixados em cada face, um a um. Para tal fim, são apresentados 2 gráficos por face mostrando num deles a potência média de deslocamento nodal de cada face, e no outro a porcentagem da queda da potência média de deslocamento nodal por face.

As simulações foram realizadas introduzindo ao modelo da face um ADV de cada vez, até no máximo 6 ADVs, de massas de 5, 10, 20, 30, 40 e 80 kg. Estes gráficos mostram a potência média de deslocamento $P$ de cada face à medida que os ADVs são adicionados nos novos pontos de maior amplitude. Em cada simulação a massa dos ADVs é sempre a mesma.

\subsubsection{Análise do modelo da face frente aos prédios}

Na face frente aos prédios as curvas da Fig. 5.14 e da Fig. 5.15 mostram que independentemente da massa utilizada 4 ADVs conseguem diminuir satisfatoriamente a potência média de deslocamento $P$. Adicionar mais um ADV não reduz esta potência. Com a utilização de $4 \mathrm{ADVs}$ de $80 \mathrm{~kg}$ consegue-se diminuir a potência média de deslocamento de $8,5 \times 10^{-9} \mathrm{~m}^{2}$ até $4,25 \times 10^{-9} \mathrm{~m}^{2}$ o que representa uma queda de potência média de deslocamento de $50 \%$. 


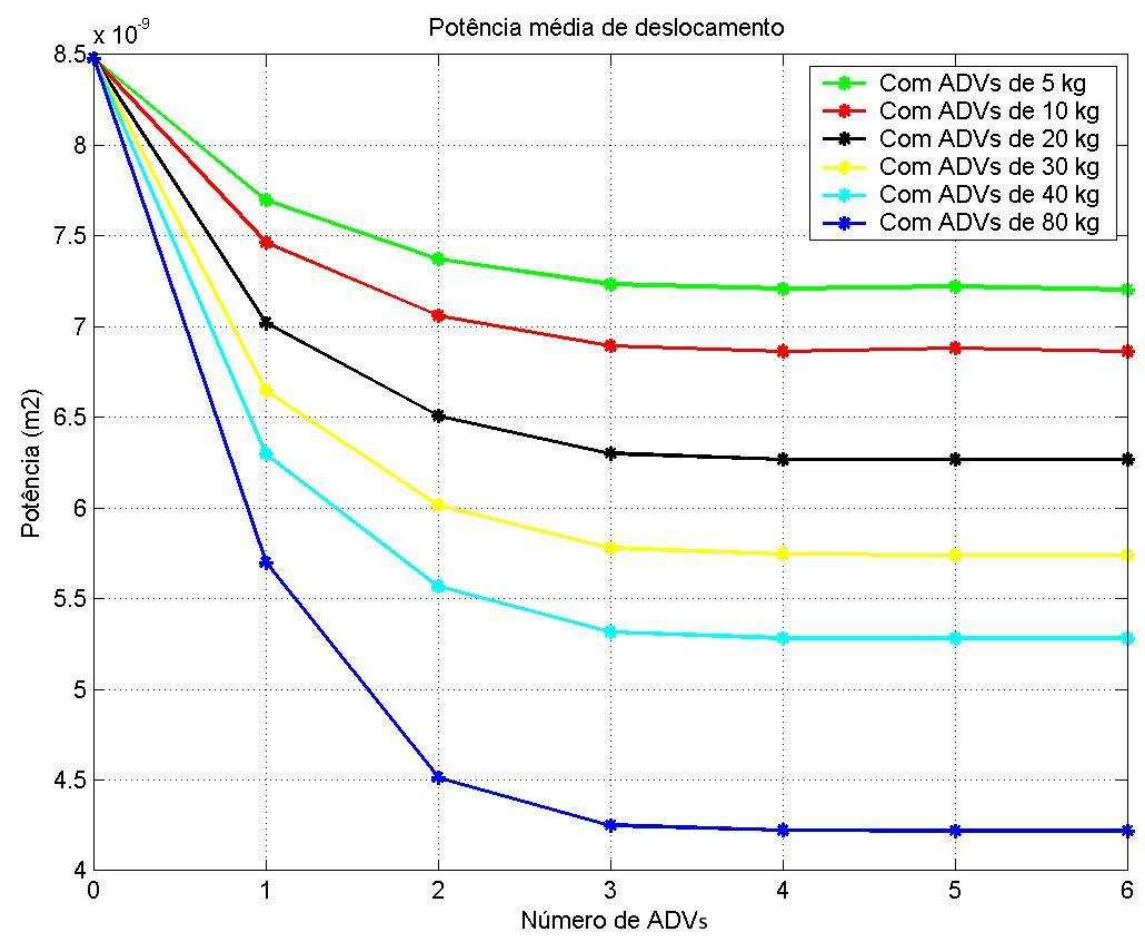

Figura 5.14: Potência média de deslocamento da face frente aos prédios

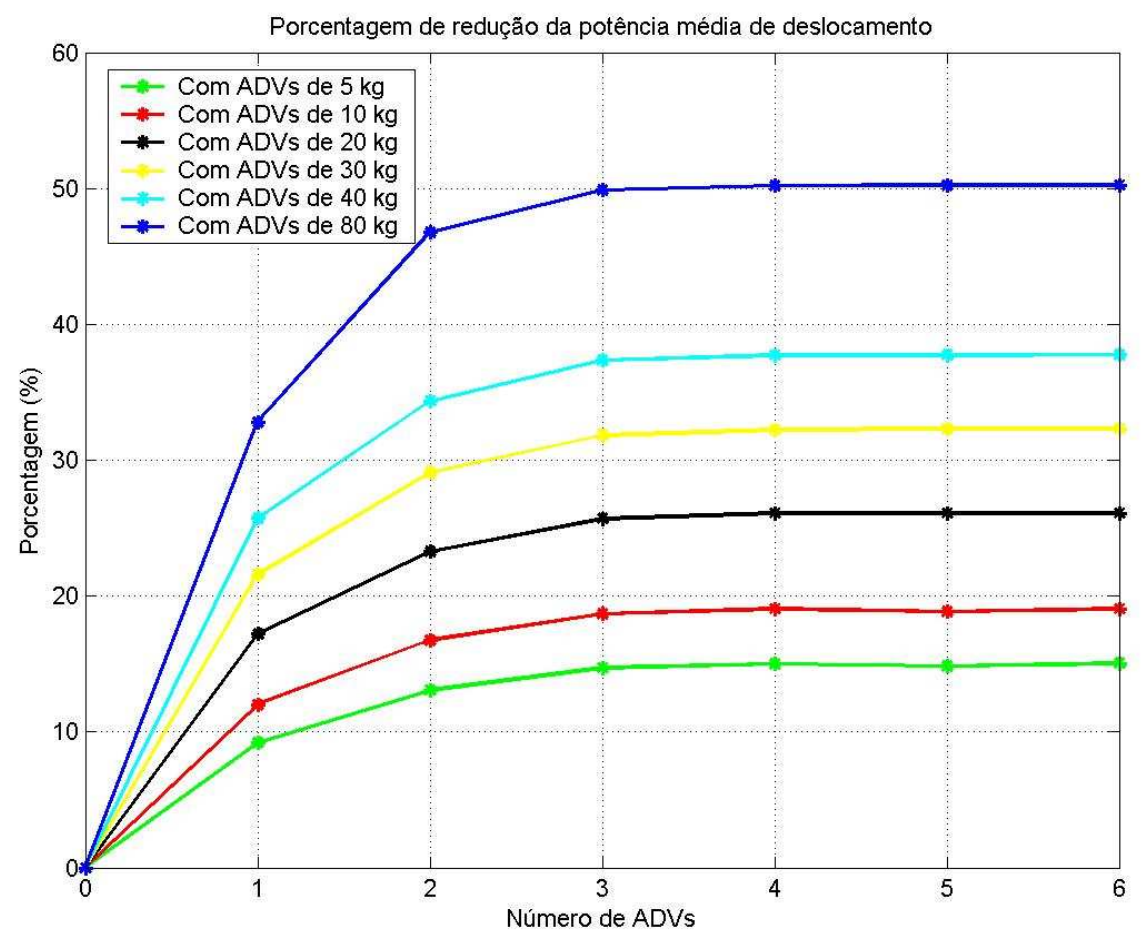

Figura 5.15: Porcentagem da queda da potência média de deslocamento na face frente aos prédios 


\subsubsection{Análise do modelo da face oposta aos prédios}

Na face oposta aos prédios as curvas da Fig. 5.16 e da Fig. 5.17 mostram que independentemente da massa utilizada 6 ADVs conseguem diminuir satisfatoriamente a potência média de deslocamento $P$. Adicionar mais um ADV não reduz esta potência. Com a utilização de 6 ADVs de $80 \mathrm{~kg}$ consegue-se diminuir a potência média de deslocamento de $2,85 \times 10^{-10} m^{2}$ até $0,83 \times 10^{-10} m^{2}$ o que representa uma queda de potência média de deslocamento de $69 \%$.

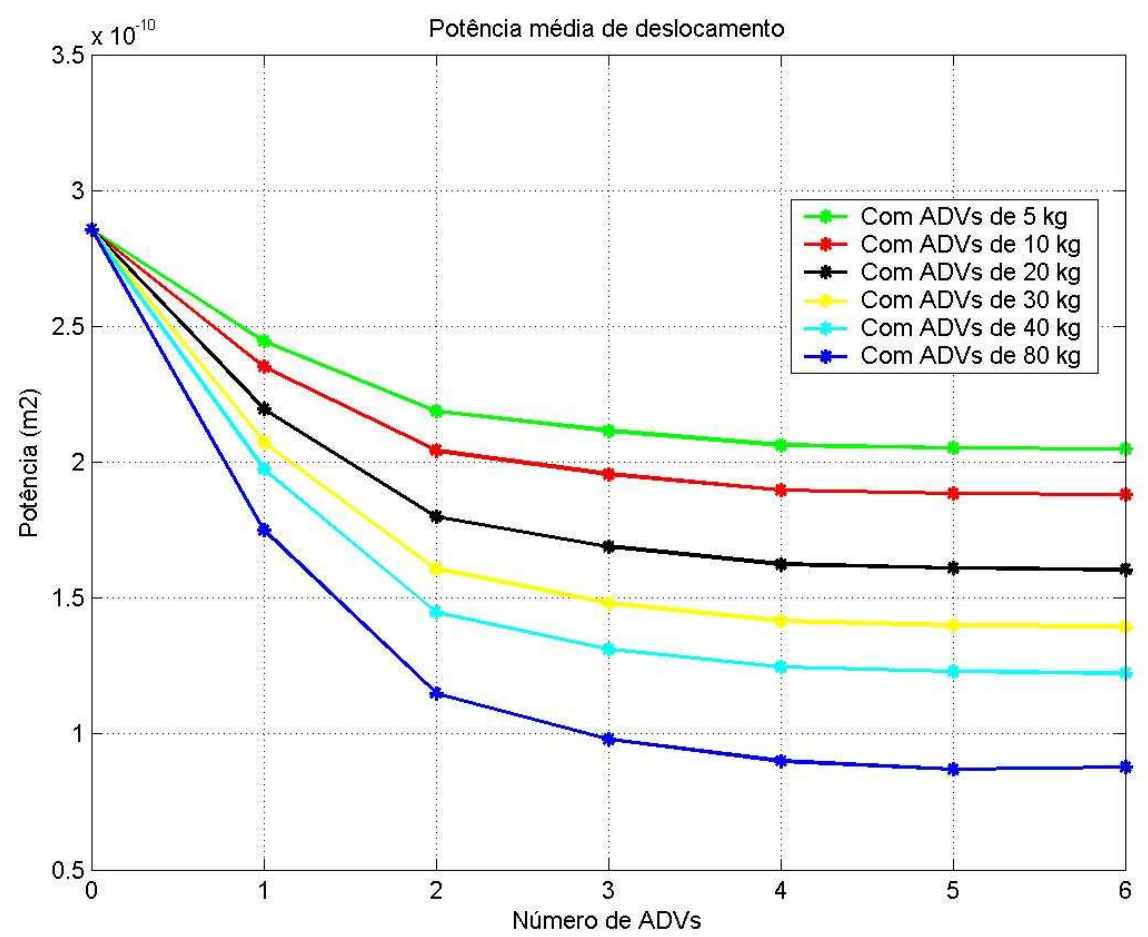

Figura 5.16: Potência média de deslocamento da face oposta aos prédios 


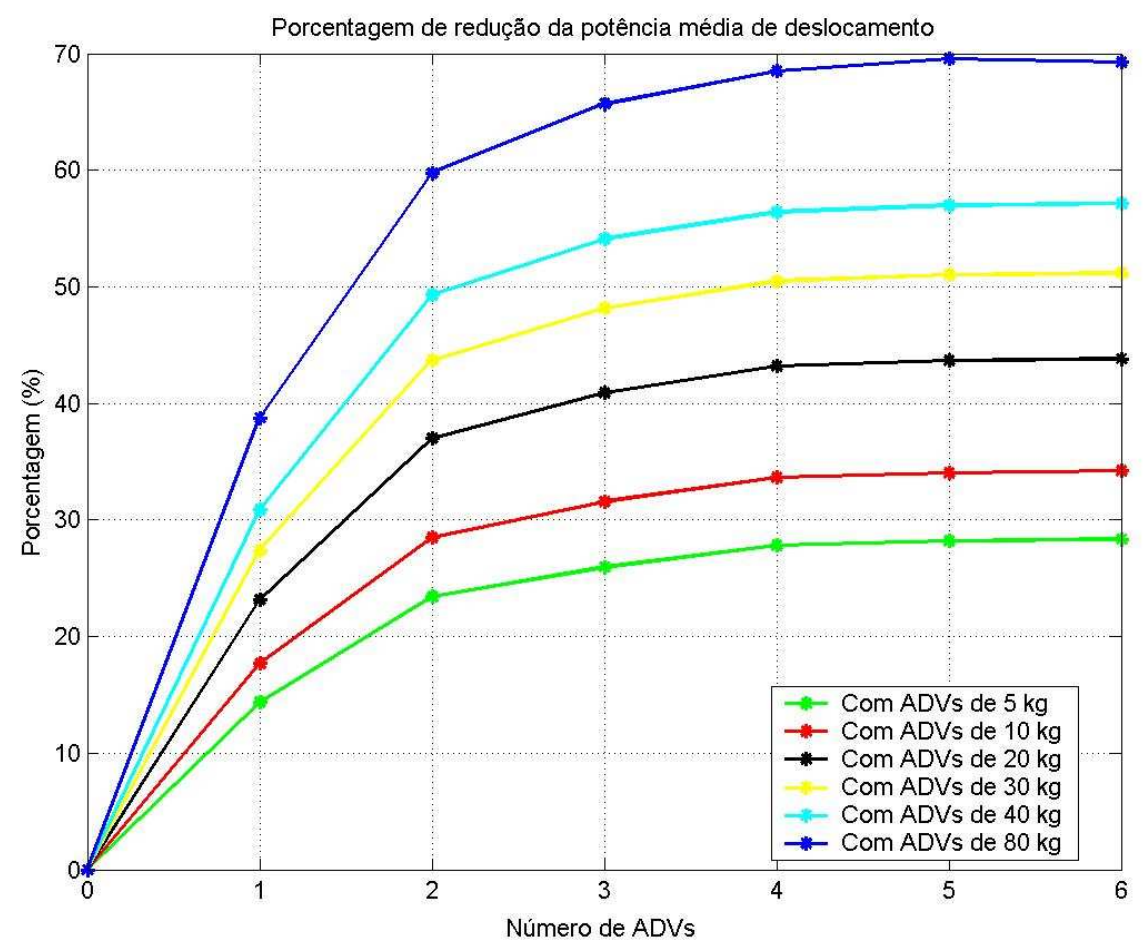

Figura 5.17: Porcentagem da queda de potência média de deslocamento na face oposta aos prédios

\subsubsection{Análise do modelo da face frente à rua}

Na face frente à rua as curvas da Fig. 5.18 e da Fig. 5.19 mostram que independentemente da massa utilizada 5 ADVs conseguem diminuir satisfatoriamente a potência média de deslocamento $P$. Adicionar mais um ADV não reduz esta potência. Com a utilização de 5 ADVs de $80 \mathrm{~kg}$ consegue-se diminuir a potência média de deslocamento de $4,7 \times 10^{-9} \mathrm{~m}^{2}$ até $1,5 \times 10^{-9} \mathrm{~m}^{2}$ o que representa uma queda de potência média de deslocamento de $68,5 \%$. 


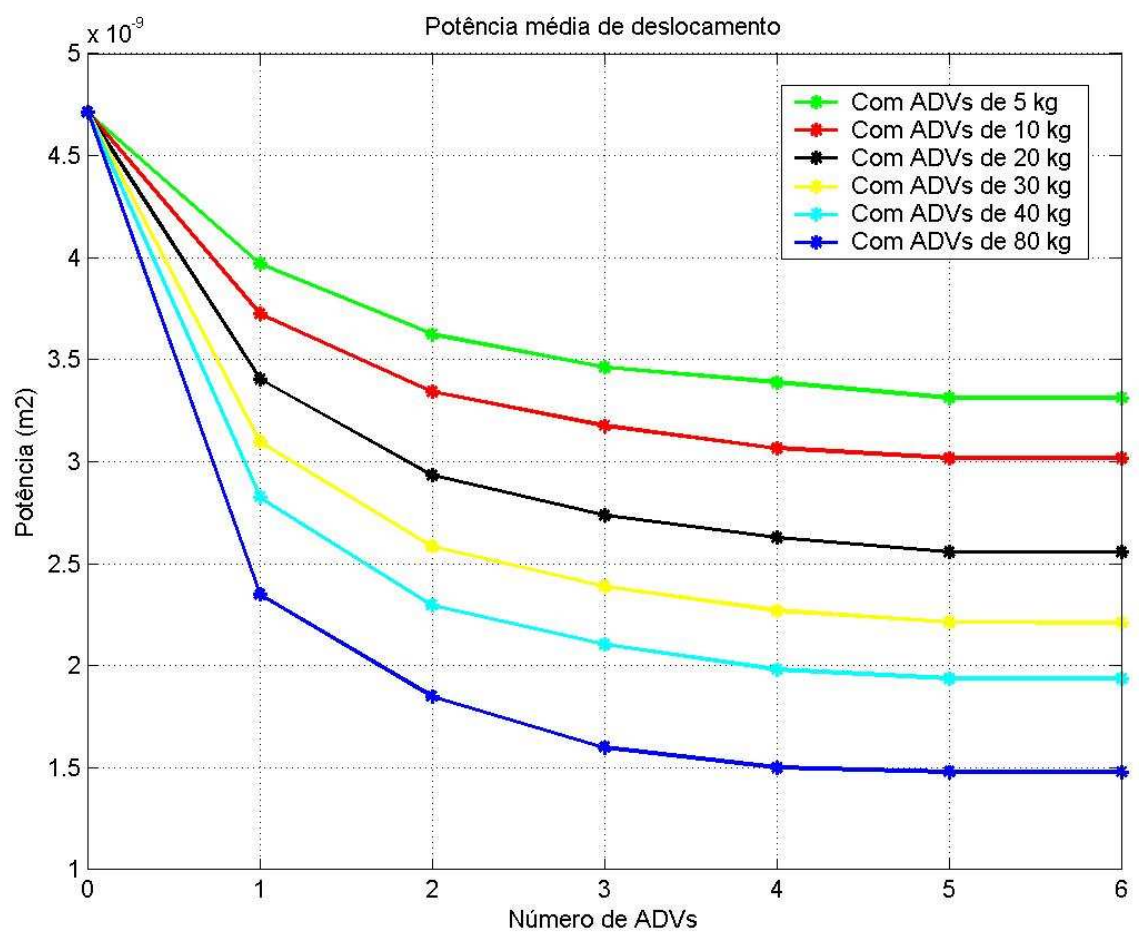

Figura 5.18: Potência média de deslocamento da face frente à rua

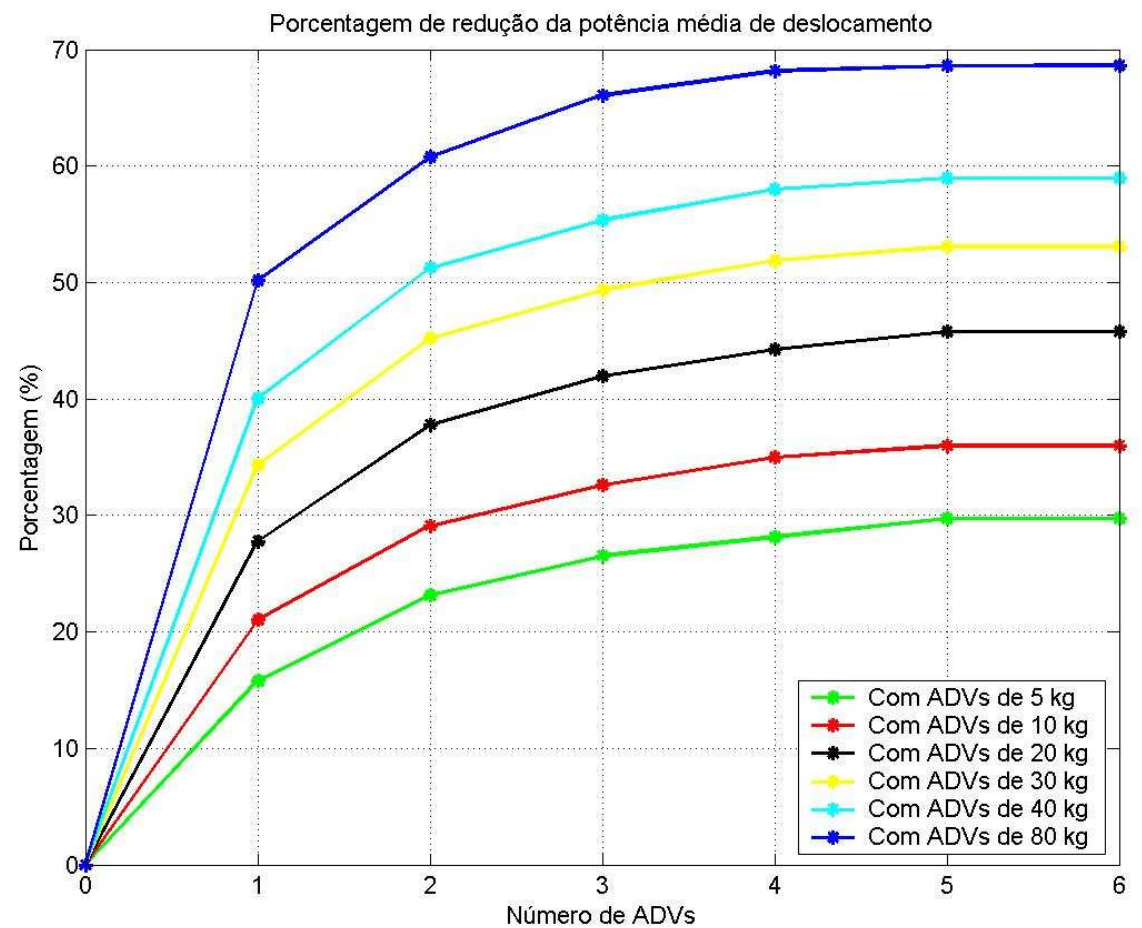

Figura 5.19: Porcentagem da queda de potência média de deslocamento na face frente à rua 


\subsubsection{Análise do modelo da face oposta à rua}

Na face oposta à rua as curvas da Fig. 5.20 e da Fig. 5.21 mostram que independentemente da massa utilizada 6 ADVs conseguem diminuir satisfatoriamente a potência média de deslocamento $P$. Adicionar mais um ADV não reduz esta potência. Com a utilização de 6 ADVs de $80 \mathrm{~kg}$ consegue-se diminuir a potência média de deslocamento de $9,55 \times 10^{-12} \mathrm{~m}^{2}$ até $4,00 \times 10^{-12} m^{2}$ o que representa uma queda de potência média de deslocamento de $58,5 \%$.

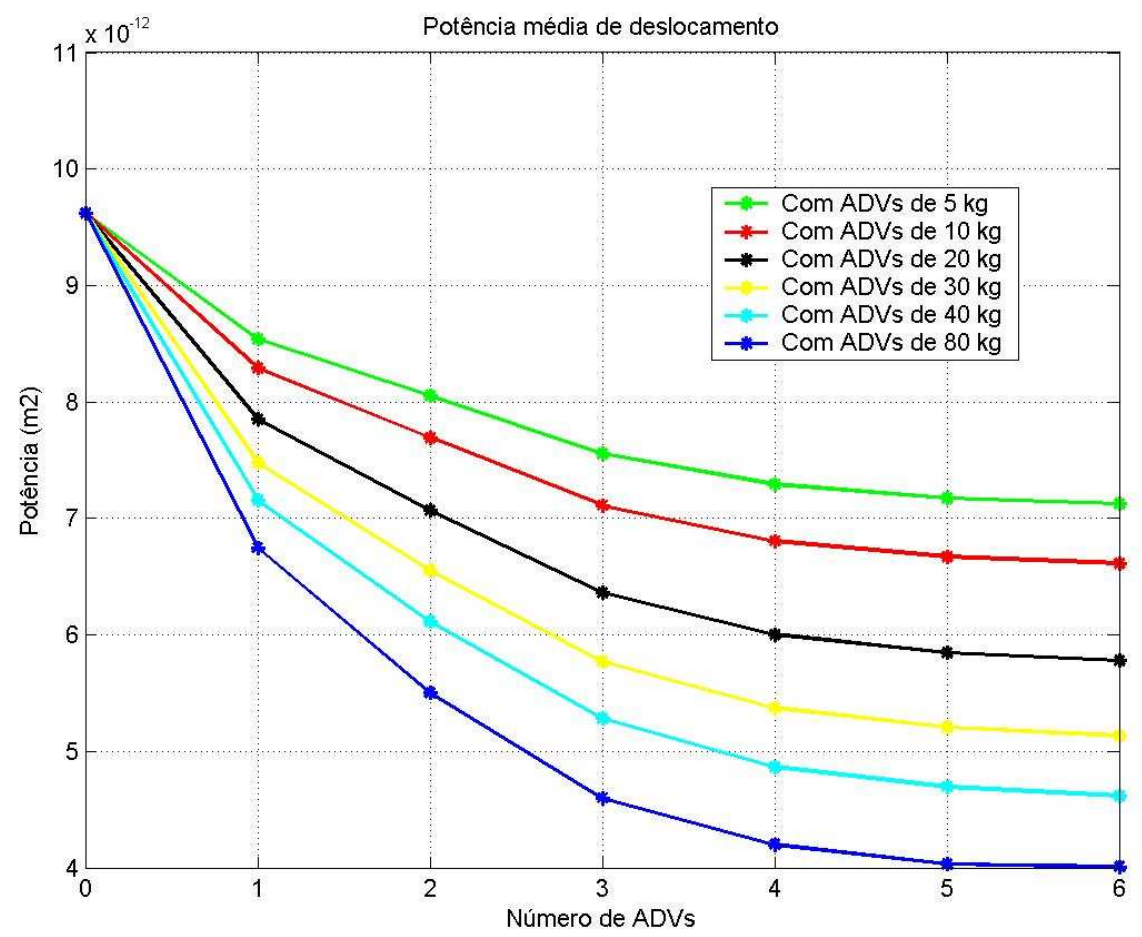

Figura 5.20: Potência média de deslocamento da face oposta à rua 


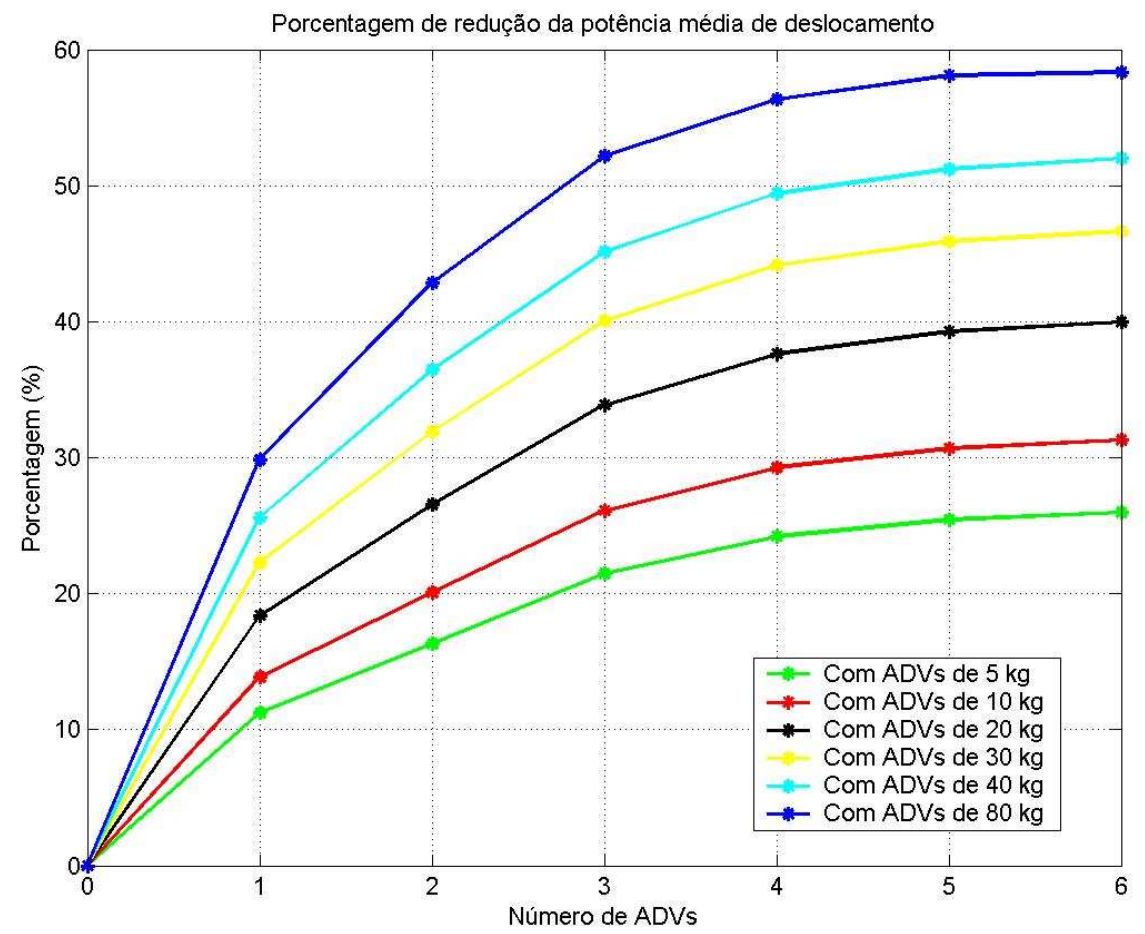

Figura 5.21: Porcentagem da queda de potência média de deslocamento na face oposta à rua

\subsection{Análise da redução de ruído acústico}

Através dos gráficos da queda da potência média de deslocamento das 4 faces estudadas, e mediante a utilização da Eq. 4.4, pode-se obter uma relação entre a porcentagem de redução da queda de potência média de deslocamento e a redução de intensidade de nível de ruído acústico como se mostra na Fig. 5.22. Neste gráfico mostra-se que utilizando ADVs de $5 \mathrm{~kg}$ consegue-se reduzir a queda de potência média de deslocamento em $10 \%$ que representa uma redução de ruído acústico de $0,5 d B$; e utilizando ADVs de $80 \mathrm{~kg}$ consigue-se reduzir a queda de potência média de deslocamento em aproximadamente $70 \%$ que representa uma redução de ruído acústico de $5,2 d B$. 


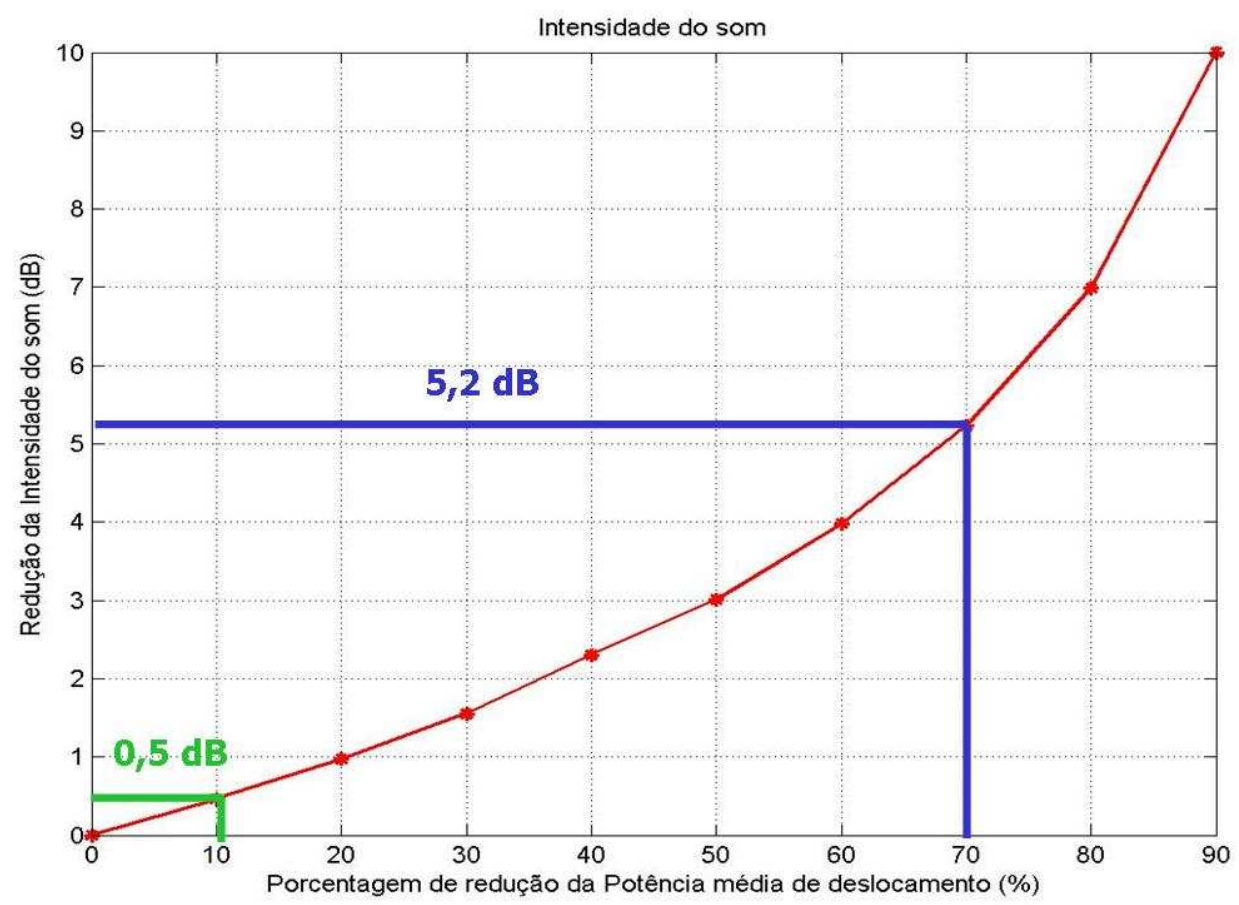

Figura 5.22: Redução da intensidade de ruído acústico 


\section{DISCUSSÃO}

A rotação de corpo rígido do transformador alerta para o fato que o suporte do transformador influencia a vibração e a emissão de ruído do transformador. Para minimizar a rotação de corpo rígido do tanque sugere-se adicionar na base do modelo amortecedores viscosos. Este movimento de corpo rígido pode excitar vibração nas faces do tanque e deve ser atenuado.

Neste trabalho foram obtidos campos de deslocamento com qualidade superior aos campos de deslocamento obtidos pela empresa $01 \mathrm{~dB}$-Brasil em virtude do tratamento de sinais realizado. Trata-se de uma seqüencia de filtragem passa-banda na freqüência intercaladas por integração no tempo.

A qualidade dos campos de deslocamento em cada face permitiu uma identificação dos pontos de maior amplitude de deslocamento e permitiu a construção de um modelo de carregamento da estrutura proporcional ao campo de deslocamentos. A hipótese de que o carregamento é proporcional ao campo de deslocamentos é uma hipótese não testada e portanto, todas as conclusões aqui geradas dependem da validade desta hipótese.

Utilizar absorvedores dinâmicos com a mesma massa constitui um procedimento subótimo. Portanto, os resultados de atenuação de potência média de deslocamento obtidos neste trabalho podem estar sub-estimados. Para otimizar a eficácia dos absorvedores dinâmicos, o ideal teria sido utilizar um método de otimização do tipo Monte Carlo Cadeias de Markov ou Simulated Annealing. Entretanto, estes métodos requerem modelos fidedignos do transformador. Na ausência destes modelos fidedignos, um procedimento experimental realizável numa sub-estação em operação, como descrito neste trabalho, parece ser um procedimento adequado para avaliar a eficácia desta técnica, no atual estágio da tecnologia deste assunto.

A redução de potência média de deslocamento é da ordem de $60 \%$ que representa uma redução de nível de ruído acústico de $5 d B$, o que sugere que a técnica de reduzir a vibração através de absorvedores dinâmicos é viável do ponto de vista físico, esta redução 
pode ser aumentada através de um aumento da massa sísmica dos absorvedores dinâmicos e do emprego de outra metologia para posicionar os absorvedores dinâmicos. A concavidade para baixo nos gráficos de redução da potência média de deslocamento parece ser decorrente do particular procedimento de alocação de absorvedores dinâmicos. 


\section{COMENTÁRIOS FINAIS}

Subordinada ao particular modelo de carregamento, carregamento proporcional aos deslocamentos em operação, e ao particular procedimento de alocação de absorvedores dinâmicos, colocar um absorvedor dinâmico de cada vez, de mesma massa sísmica, no novo ponto de máximo deslocamento, verificou-se que

1. o número de absorvedores dinâmicos em cada face variou de 4 a 6 ;

2. a atenuação da potência média de deslocamento em cada face aumentou com o aumento da massa sísmica do absorvedor dinâmico;

3. restringindo a massa sísmica a $80 \mathrm{~kg}$ foi possível reduzir a potência média de deslocamento das faces de $50 \%$ a $70 \%$ dependendo da face;

4. a porcentagem de redução da potência média de deslocamento na face frente aos prédios, utilizando seis absorvedores dinâmicos de $80 \mathrm{~kg}$ de massa, foi de $50 \%$;

5. a porcentagem de redução da potência média de deslocamento na face oposta aos prédios, utilizando seis absorvedores dinâmicos de $80 \mathrm{~kg}$ de massa, foi de $69 \%$;

6. a porcentagem de redução da potência média de deslocamento na face frente à rua, utilizando seis absorvedores dinâmicos de $80 \mathrm{~kg}$ de massa, foi de 68,5\%;

7. a porcentagem de redução da potência média de deslocamento na face oposta à rua, utilizando seis absorvedores dinâmicos de $80 \mathrm{~kg}$ de massa, foi de 58,5\%;

Estes fatos sugerem, subordinados ao modelo de carregamento do tanque e ao método de alocação dos absorvedores, que o emprego de absorvedores dinâmicos permitem reduções significativas no ruído acústico emitido por transformadores de potência, quando parte significativa deste ruído está concentrado numa faixa estreita na freqüência. 


\section{Referências}

ABNT. Avaliação do ruído em áreas habitadas visando o conforto da comunidade. Acústica, p. 4-9, 2000.

BIES, D.; HANSEN, C. E \& fn. Engineering Noise Control, p. 147, 1996.

BURIAN, J. J. Circuitos Elétricos, Magneticos e Teoria Eletromagnética. 1a. ed. [S.1.]: Ábaco Livraria Ltda., 1991.

CUNHA, J. S. S. Estudo numérico e teórico de absorvedores dinâmicos de vibração. Dissertação de mestrado, Universidade Federal de Uberlândia, 1999.

FARIAS, A. P.; BISTAFA, S.; DELALlO, S. D.; GRIMONI, J. A. Aplicação da legilação ambiental no meio urbano - controle de ruído em subestação. 1997.

FERREIRA, J. L. Proposes for reduction and attenuation of noises coming from electrical high-power transformers and substations. PROMEC-UFRGS, 2006.

FIliPPiN, C. G.; BAVASTRI, C. A.; KUleviCZ, D. A. L.; BORRELli, A. Q.; SANTOS, H. L. V. dos; AUERSVALD, R. C. Medição e controle de vibração e ruído em transformadores de subestações. II Congresso de Inovação Tecnológica em Energia Elétrica, p. 1106-1112, 2003.

FRAHM, H. Device for damping vibrations of bodies. US Patent, p. 958-989, 1911.

GARCIA-SOUTO, J. A.; LAMELA-RIVERA, H. Comparative analysis of optical-fibre interferometric sensors versus accelerometers: Application to vibrations inside high-power transformers. Optoeletronics and Laser Technology Group, p. 9, 2002.

GARCíA, B.; BURGOS, J. C.; ALONSO, A. M. Transformer tank vibration modeling as a method of detecting winding deformations - part i: Theorical foundation. IEE Transactions on Power Delivery, v. 21, n. 1, p. 157-163, January 2006.

HARTOG, D. J. P. Vibration in systems mechanics. 1a. ed. [S.1.]: McGraw-Hill Book Company,inc, 1972.

HESSELMANN, N. Investigation of noise reduction on a 100 kva transformer tank by means of active methods. Applied Acoustics, n. 11, p. 27-34, 1978.

HUANG, C. R.; FULLER, C. R. The effects of dynamic absorbers on the forced vibration of a cylindrical shell and its coupled interior sound field. Journal of Sound and Vibration, n. 200(4), p. 401-418, 1997.

IEEE. Iee guide for sound level abatement and determination for liquid-immersed power transformers and shunt reactors rated over 500 kva. Power Engineering Society, p. 1-23, 2000 . 
JASINSKI, R.; CALOMENO, R. A.; FILIPPIN, C.; KUlEVICZ, D.; BAVASTRI, C. Controle de ruído em transformadores de subestações com neutralizadores dinâmicos. Seminário Nacional de Produção e Transmissão de energia elétrica, p. 1-8, Outubro 2005.

KORONEV, B. G.; REZNIKOV, L. M. Vibration absorbers. Theory and techical applications. 1a. ed. [S.l.]: John Wiley \& Sons, 1993.

MARTIGNONE, A. Transformadores. Globo. [S.1.: s.n.], 1971. 307 p.

MEDEIROS, E. B.; KROEFF, G. Acoustic modelling and simulation of an urban substation. Proceedings of the 16th International Congress on Acoustics, 1998.

MIZOKAMI, M.; YABUMOTO, M.; OKAZAKI, Y. Vibration analiysis of 3-phase model transformer core. Electrical Engineering in Japan, v. 119, n. 1, p. 1-8, 1997.

RAM, Y. M.; ELHAY, S. The theory of a multi degree of freedom dynamic absorver. Journal of Sound and Vibration, p. 607-615, 1996.

RAUSCH, M.; KALTENBACHER, M.; LANDES, H.; LERCH, R.; ANGER, J.; GERTH, J.; BOSS, P. Combination of finite and boundary element methods in investigation and reduction of load-controlled noise of power transformer. Journal of Sound and Vibration, n. 250(2), p. 323-338, 2002.

REYNE, G.; MAGNIN, H.; BERLIAT, G. A supervisor for the succesive 3d computations of magnetic, mechanical and acoustic quantities in power oil inductors and transformers. IEE Transactions on Magnetics, v. 30, n. 5, p. 3292-3295, September 1994.

RODRIGUES, V. F.; MEDEIROS, E. B.; PAVANELlO, L. Mapeamento preliminar de emissão acústica em uma subestação elétrica urbana. Anais do I Congresso Iberoamericano de Acústica, 1998.

SIEMENS LTDA. Transformadores de Força. [S.l.]: Catálogo técnico, 2001. 12 p.

UCB. Controle da poluição sonora. Gestão Ambiental e Qualidade de Vida Urbana, p. $1-15,2001$.

WHO. World healh organization regional office for europe. Noise and Sleep, 2004. 


\section{Apêndice A - Conceitos utilizados}

Nesta seção apresentam-se alguns conceitos importantes para o entendimento deste trabalho.

\section{A.1 Decibel}

Denomina-se decibel à unidade relativa usada em Acústica e Telecomunicações, para expressar a relação entre duas magnitudes (acústicas ou elétricas), ou entre a magnitude que é estudada e uma magnitude de referência.

O decibel, (símbolo dB) é uma unidade logarítmica, que é 10 vezes o logaritmo decimal da relação entre a magnitude de interesse e a de referência. O bel é o logaritmo da relação entre a magnitude de interesse e a de referência, mas não é utilizada por ser demasiado grande na prática.

O bel recebeu esse nome por Alexander Graham Bell, tradicionalmente considerado como inventor do telefone. Um (1) bel (unidade original) equivale a 10 decibéis e representa um aumento de potência de 10 vezes (1 é o logaritmo decimal de 10) sobre a magnitude de referência. Zero bels é o valor da magnitude de referência (0 é o logaritmo de 1). Assim, dois bels representam um aumento de cem vezes (2 é o logaritmo decimal de 100) na potência, 3 bels equivalem a um aumento de mil vezes ( 3 é o logaritmo decimal de 1.000), e assim sucessivamente.

Como o decibel é uma unidade relativa, para saber a intensidade de um som toma-se como $0 \mathrm{~dB}$ a intensidade de 20micropascales $=(d B S P L)$. A escala compreende entre o mínimo som que o ouvido humano pode detectar (20 micropascales), e o som mais forte (mais de 180 dB), o ruído de um foguete durante o lançamento.

Os decibéis se medem logarítmicamente. Isto significa que a intensidade se incrementa em unidades de 10, cada incremento é 10 vezes maior que o anterior, 20 decibéis é 10 vezes a intensidade de $10 \mathrm{~dB}$, e $30 \mathrm{~dB}$ é 100 vezes mais intenso que $10 \mathrm{~dB}$. 
O umbral de audição é de $0 \mathrm{~dB}$ (mas é um dado que muda entre distintas pessoas e dentro da mesma pessoa, para distintas freqüências). O umbral de dor, encontra-se em torno dos $140 \mathrm{~dB}$; o ouvido não responde igual a todas as freqüências de ruído, vale dizer, que são ouvidos alguns sons melhor que outros, dependendo da freqüência. Motivo pelo qual definiu-se o decibel $\mathbf{A}$ (dBA), como a unidade de nível sonoro medido com um filtro prévio que tira parte das baixas e altas freqüências. Desta forma, depois da medição filtra-se o som para conservar somente as freqüências mais prejudiciais para o ouvido, causa pela qual a exposição medida em dBA é um bom indicador de risco auditivo.

O som mais débil que um ouvido pode escutar ou detectar tem um valor eficaz de vinte milionésimas de um pascal $(20 \mu \mathrm{Pa})$, algo assim como 5.000.000.000 vezes menos que a pressão atmosférica normal. Considera-se que não devem se registrar mais de 30 decibéis para que uma pessoa consiga dormir bem, enquanto que 140 decibéis constituem o umbral do suportável.

\section{A.2 Lei de Lenz}

De acordo com os estudos de Michael Faraday, a variação do fluxo magnético próximo a um condutor cria uma corrente (denominada corrente induzida). Não havendo variação do fluxo magnético, não há a ocorrência de uma corrente induzida. Esta variação pode acontecer:

1.Com um campo magnético constante,

-afastamento do condutor ou da fonte magnética (diminuição do fluxo);

-aproximação do condutor ou da fonte magnética (aumento do fluxo);

•variação da área da espira;

- giro da espira.

2.Com a variação do campo magnético da fonte magnética.

A indução eletromagnética é o princípio fundamental sobre o qual operam transformadores, geradores, motores elétricos e a maioria das demais máquinas elétricas. A corrente elétrica é diretamente proporcional ao fluxo magnético dentro de um determinado tempo.

Segundo a lei de Lenz, o sentido da corrente é o oposto da variação do campo magnético que a gera. Havendo diminuição do fluxo magnético, a corrente criada gerará um campo magnético de mesmo sentido do fluxo magnético da fonte. Havendo aumento, a 
corrente criada gerará um campo magnético oposto ao sentido do fluxo magnético da fonte.

Imagine uma espira circular no mesmo plano da tela submetida a um fluxo magnético constante (portanto sem corrente induzida) e "entrando"na tela. Dependo da movimentação dada à espira, ocorrerá aumento ou diminuição do fluxo magnético e, com base nesse movimento, podemos determinar o sentido da corrente induzida criada como:

-Afastamento (diminuição do fluxo magnético): sentido horário.

-Aproximação (aumento do fluxo magnético): sentido anti-horário.

\section{A.3 Operating Deflection Shape}

ODS (Forma de Deflexão Operancional) é uma técnica que permite obter a resposta de vibração em múltiplos pontos e direções de uma estrutura, utilizando um moderno sistema de aquisição de dados multicanal. As funções de transferência são calculadas entre um sensor de referência local e todos os outros sensores posicionados em diversas partes da estrutura, permitindo assim, obter informações de fase e amplitude sobre o movimento de uma máquina em operação; onde o próprio funcionamento da máquina é quem fornece as forças de excitação para as medições coletadas, sem precisar de uma excitação externa como é o caso da Função de Resposta em Freqüência (FRF).

Após realizadas as medições, um programa computacional analisa todos os dados para reproduzir uma série de animações em 3D, mostrando o movimento da máquina para diferentes freqüências selecionadas. O análise ODS fornece informações sobre a forma em que deve ser modificada uma estrutura para resolver um problema de vibrações, já que permite localizar os deslocamentos máximos e mínimos de dita estrutura.

\section{A.4 Parâmetros espectrais}

A avaliação do espectro de um sinal pode ser realizada pela aplicação da transformada de Fourier. No caso de um sinal digitalizado, pode ser aplicada a TDF (Transformada Discreta de Fourier), e que mantém, dentro de certas limitações, as mesmas características da primeira. A transformada de Fourier é uma transformação matemática que leva a informação do domínio temporal para o domínio em freqüência. Ela é obtida através da série de Fourier. A série de Fourier é aplicada para sinais periódicos com período definido 
e pode ser escrita em diversas formas. As equações A.1 e A.2 descrevem duas destas formas:

$1^{a}$ forma (decomposição em senos e co-senos)

$$
\begin{gathered}
x_{t}=a_{0}+\sum_{n=1}^{\infty}\left[a_{n} \cos \left(2 \pi n f_{0} t+b_{n} \operatorname{sen}\left(2 \pi n f_{0} t\right)\right)\right] \\
\text { onde: } f_{0}=\frac{1}{T_{0}} \text { é a freqüência fundamental. } \\
n f_{0}=1,2, \ldots, \infty \text { são os harmônicos. }
\end{gathered}
$$

E os coeficientes $a_{0}, a_{n}$ e $b_{n}$ são obtidos por:

$$
\begin{gathered}
a_{0}=f_{0} \int_{\tau}^{\tau+T_{0}} x(t) d t \text { (valor médio) } \\
a_{n}=2 f_{0} \int_{\tau}^{\tau+T_{0}} x(t) \cos \left(2 \pi n f_{0} t\right) d t, \mathrm{n}=1,2,3, \ldots \\
b_{n}=2 f_{0} \int_{\tau}^{\tau+T_{0}} x(t) \operatorname{sen}\left(2 \pi n f_{0} t\right) d t, \mathrm{n}=1,2,3, \ldots
\end{gathered}
$$

$2^{a}$ forma (complexa)

$$
\begin{gathered}
x(t)=\sum_{n=-\infty}^{\infty} X_{n} e^{2 \pi j n f_{0} t} \\
\text { onde: } X_{n}=f_{0} \int_{0}^{T o} x(t) e^{-2 \pi j n f_{0} t} d t \\
n=0, \pm 1, \pm 2, \pm 3 \ldots
\end{gathered}
$$

Sendo $X_{n}$ complexo:

As amplitudes da série são:

$$
X_{n}=a_{n}-j b_{n}
$$

$$
\left|X_{n}\right|=\sqrt{a_{n}^{2}+b_{n}^{2}}
$$


E as fases da série são:

$$
\varphi=\operatorname{arctg}\left(\frac{b_{n}}{a_{n}}\right)
$$

Esta ferramenta matemática (série de Fourier) para modificação do domínio do sinal é muito útil e importante nas análises de sinais periódicos, e seria interessante poder utilizá-la também em sinais não periódicos, mas para isso precisamos assumir que o sinal não periódico é limitado e possui uma periodização. Assim, levado o termo $T_{0}$ para o infinito, obtendo desse limite a integral de Fourier descrita na equação A.6.

$$
X_{f}=\int_{-\infty}^{\infty} x(t) e^{-2 \pi j f t} d t
$$

Esta integral pode ser calculada numericamente conservando as características da integral contínua. A este método dá-se o nome da Transformada Discreta de Fourier (TDF). Posteriormente descobriu-se um algoritmo computacional mais rápido para cálculo da TDF. A este novo algoritmo deu-se o nome de Transformada Rápida de Fourier ou (FFT) e se baseia na simetria da transformada desde que o sinal analisado tenha um número de pontos que seja uma potência de dois. A TDF é calculada conforme a equação A.7.

$$
X_{(m \triangle f)}=\sum_{n=0}^{n=a} x_{n}(\triangle t) e^{-j 2 \pi(m \triangle f)(n \triangle t)}
$$

\section{A.5 Calculix}

Calculix é um código (fonte) aberto para aplicações analíticas através dos elementos finitos, que usa um formato semelhante ao utilizado para o ABAQUS. Tem um solver implícito e explícito (CCX), escrito por Guido Dhondt e um pré e pós-processador (CGX) escrito por Klaus Wittig. O software original foi escrito para o sistema operacional Linux, mas a convergência de soluções mecânicas tem portado o pedido para o sistema operacional Windows. 
CalculiX é um pacote destinado a resolver problemas de campo. O método utilizado é o método dos elementos finitos. Com CalculiX os modelos baseados em Elementos Finitos podem ser construídos, calculados e pós-processados. O pré e pós-processador é uma ferramenta interativa 3D usando o openGL API. O solver é capaz de fazer cálculos lineares e não lineares. Soluções estáticas, dinâmicas e térmicas estão disponíveis. Ambos programas podem ser utilizados de forma independente, porque o solver faz uso do formato de entrada abaqus, tão bem é possível utilizar pré-processadores comerciais. O pré-processador é capaz de escrever dados de malhas relacionados à nastran, abaqus, ansys, código-aster e para os livres-cfd códigos duns, ISAAC e OpenFOAM. A vda CAD interface está disponível. O programa é projetado para ser executado em plataformas Unix assim como Linux e computadores Irix, mas também em MS - Windows.

CalculiX foi desenvolvido por uma equipe de entusiastas em seus tempos livres, empregados da MTU Munique, fabricantes da Aero Engine na Alemanha, quem concedeu a publicação. 


\section{Apêndice B - Modelo com duas massas e duas molas para definir a freqüência do ADV}

Considere um modelo com dois graus de liberdade, duas massas e duas molas (ver Fig.B.1). A massa maior deve representar uma região de uma das faces do tanque, a massa menor deve representar a massa do absorvedor dinâmico. Através deste modelo é possível determinar por simulação numérica que a freqüência natural do ADV deve ser um pouco superior à freqüência da vibração da base, da massa maior.

Sejam $k_{1}, c_{1}$, e $m_{1}$, a representação esquemática de uma região de uma face do transformador com a força $F(t)$ agindo sobre ela. O ADV amortecido deve consistir num sistema vibratório comparativamente pequeno com: $k_{2}, c_{2}$, e $m_{2}$, ligado à massa principal $m_{1}$. A freqüência natural $\sqrt{\frac{k}{m}}$ do absorvedor, deve ser escolhida de forma a maximizar a energia cinética no absorvedor dinâmico e a minimizar a energia cinética da massa $m_{1}$.

As equações de movimento para a representação esquemática do modelo utilizado neste trabalho são:

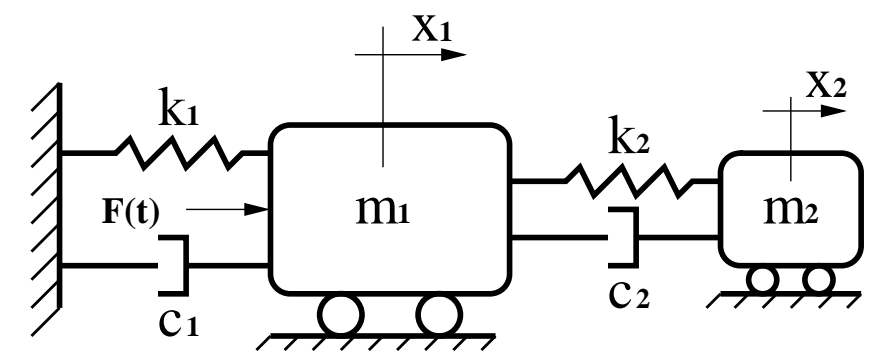

Figura B.1: Esquema do modelo utilizando ADV amortecido

$$
\begin{gathered}
m_{1} \ddot{x_{1}}+k_{1} x_{1}-k_{2}\left(x_{2}-x_{1}\right)+c_{1} \dot{x_{1}}-c_{2}\left(\dot{x_{2}}-\dot{x_{1}}\right)=F(t) \\
m_{2} \ddot{x_{2}}+c_{2}\left(\dot{x_{2}}-\dot{x_{1}}\right)+k_{2}\left(x_{2}-x_{1}\right)=0
\end{gathered}
$$


Verifica-se que quando a freqüência natural do ADV é ligeiramente superior à freqüência da força de excitação $f(t)$, minimiza-se a energia cinética da massa $m_{1}$ e maximiza-se a energia cinética da massa $m_{2}$. 


\section{Apêndice C - Código fonte - Tratamento dos Sinais}

Nesta seção apresentam-se o código fonte dos principais programas que permitem reproduzir o modelo do transformador em estudo.

O seguinte programa foi realizado para conseguir os sinais de deslocamento que foram introduzidos como forças proporcionais ao modelo de Elementos Finitos.

Processamento dos sinais de aceleração.m

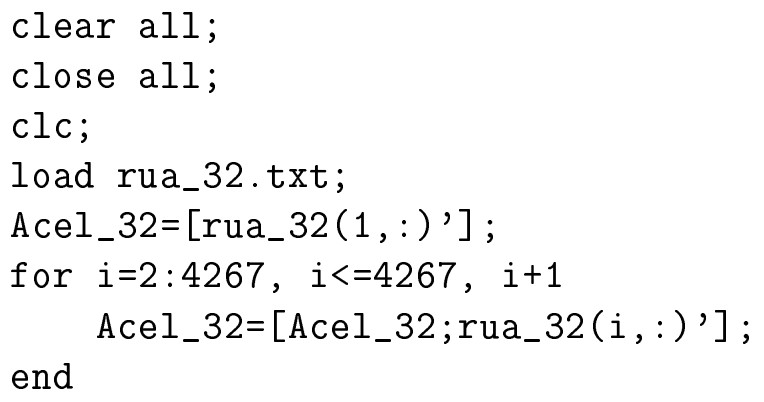


TF_Acel $(n / 2-i+1)=0.0$;

end

Acel=ifft (TF_Acel);

\% Sinal de aceleração filtrada

Acel=real (Acel) - mean (real (Acel));

plot (t,Acel);

title('Sinal de Aceleração ponto 32');

xlabel('t(s)');

ylabel ('Aceleração ( $\left.\mathrm{m} / \mathrm{s}^{\sim} 2\right)$ ') ;

\% Integração do sinal de aceleração no domínio do tempo

Vel=ts*cumtrapz (Acel);

$\mathrm{Vel}=\mathrm{Vel}-\mathrm{mean}(\mathrm{Vel})$;

$\%$ FFT sinal de velocidade

TF_Vel=fft $(\mathrm{Vel})$;

$\%$ Filtragem da FFT da velocidade lados extremos

$\mathrm{TF} \_\operatorname{Vel}(\mathrm{n} / 2+1)=0.0$;

for $i=1: 8800$

$\mathrm{TF} \_\operatorname{Vel}(\mathrm{n} / 2+i+1)=0.0$;

TF_Vel $(n / 2-i+1)=0.0$;

end

Vel=ifft (TF_Vel);

$\%$ Sinal de velocidade filtrada

Vel=real (Vel)-mean (real (Vel));

\%Integração do sinal de velocidade no domínio do tempo

Desl=ts*cumtrapz $(\mathrm{Vel})$;

Desl=Desl-mean (Desl);

$\%$ FFT sinal de deslocamento

TF_Desl=fft (Desl);

$\%$ Filtragem da FFT do deslocamento lados extremos

TF_Desl $(\mathrm{n} / 2+1)=0.0$;

for $i=1: 8800$

TF_Desl $(n / 2+i+1)=0.0$;

TF_Desl $(n / 2-i+1)=0.0$;

end

Desl=ifft(TF_Desl);

\% Sinal de deslocamento filtrada

Desl=real (Desl) -mean (real (Desl));

$\mathrm{A} 1=\operatorname{Des} 1(1: 109)$;

$A 2=\operatorname{Desl}(109: 217)$;

$A 3=\operatorname{Desl}(217: 325)$;

$A 4=\operatorname{Desl}(325: 433)$;

A5=Desl (433:541);

A6=Desl (541:649);

$A 7=\operatorname{Desl}(649: 757)$;

$\mathrm{A} 8=\operatorname{Desl}(757: 865)$;

$A 9=\operatorname{Desl}(865: 973)$;

A10=Desl (973:1081); 


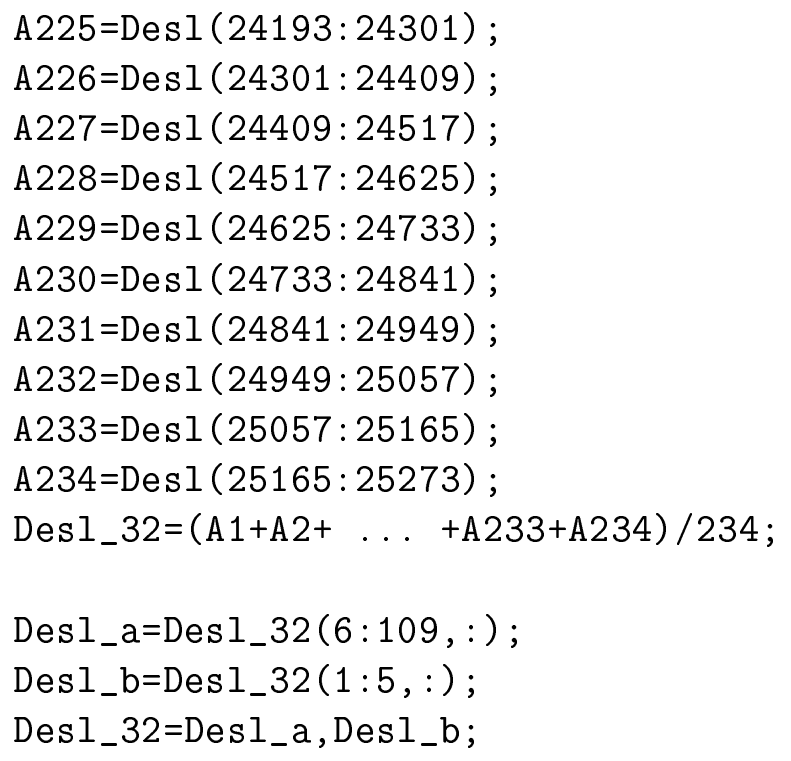




\section{Apêndice D - Arquivo de entrada para o CalculiX}

O seguinte programa foi realizado para simular o comportamento dinâmico do tanque do transformador com ADVs incorporados.

Simulação do deslocamento em operação do tanque do transformador.inp

**Simulação da face frente à rua com 6 ADVs de $20 \mathrm{~kg}$.

Model: beam Date: 22-Dez-2007

*NODE, NSET=NALL

$1,0.000000,0.000000,0.000000$

$2,0.010000,0.000000,0.000000$

$3,0.010000,5.600000,0.000000$

$4,0.000000,5.600000,0.000000$

$5,0.000000,0.000000,3.450000$

$6,0.010000,0.000000,3.450000$

$7,0.010000,5.600000,3.450000$

$8,0.000000,5.600000,3.450000$

$9,0.005000,0.000000,0.000000$

$10,0.010000,0.005000,0.000000$

$\ldots \ldots \ldots \ldots \ldots \ldots \ldots$

$6604,1.703333,-0.640000,0.902500$

$6605,1.703333,-0.640000,0.822500$

$6606,1.623333,-0.640000,0.862500$

$6607,1.663333,-0.640000,0.902500$

$6608,1.703333,-0.640000,0.862500$

$6609,1.663333,-0.640000,0.822500$

$6610,1.623333,-0.540000,0.822500$

$6611,1.623333,-0.540000,0.902500$

$6612,1.703333,-0.540000,0.902500$

$6613,1.703333,-0.540000,0.822500$ 
*ELEMENT, TYPE $=$ C3D20 , ELSET $=\mathrm{B} 0$

\begin{tabular}{|c|c|c|c|c|c|c|c|c|}
\hline 1, & 1, & 2 & 11 & 63, & 141 & 122 & 210 & 452 \\
\hline & 63 , & 11, & 13 & 61, & 452 & 210 & 212 & 450 \\
\hline
\end{tabular}

$867,5827,5794,6209,6214,5504,5376,5378,5526, \quad 5828$,

$868,6214,6209, \quad 5919, \quad 5979, \quad 5526, \quad 5378, \quad 5380, \quad 5548,6217$,

$*$ ELEMENT , TYPE $=$ C3D20 , ELSET $=\mathrm{B} 1$

**Elemento de união do ADV 1 (20 kg.) ao tanque

$869,6222,6223,6224,6225,6218,6219,6220,6221,6228,6229$, $6230,6231,808,6226,808,6227,6232,6233,6234,6235$

*ELEMENT , TYPE $=$ C3D20 , ELSET $=\mathrm{B} 2$

**Elemento da mola do ADV 1 (20 kg.)

$870,6236,6222,6223,6237,6239,6225,6224,6238,6244,6228$, $6245,6240,6247,6230,6246,6242,6243,6231,6229,6241$

$871,6248,6236,6237,6249,6251,6239,6238,6250,6256,6240$, $6257,6252,6259,6242,6258,6254,6255,6243,6241,6253$

$*$ ELEMENT, TYPE $=$ C3D20 , ELSET $=\mathrm{B} 3$

**Elemento da massa do ADV 1 (20 kg.)

$872,6260,6248,6249,6261,6263,6251,6250,6262,6268,6252$, $6269,6264,6271,6254,6270,6266,6267,6255,6253,6265$

$873,6272,6260,6261,6273,6275,6263,6262,6274,6280,6264$, $6281,6276,6283,6266,6282,6278,6279,6267,6265,6277$

$*$ ELEMENT , TYPE $=$ C3D20 , ELSET $=\mathrm{B} 1$

**Elemento de união do ADV 6 (20 kg.) ao tanque

$894,6552,6553,6554,6555,6548,6549,6550,6551,6558,6559$, $6560,6561,796,6556,796,6557,6562,6563,6564,6565$

$*$ ELEMENT, TYPE $=$ C3D20 , ELSET $=\mathrm{B} 2$

**Elemento da mola do ADV 6 (20 kg.)

$895,6566,6552,6553,6567,6569,6555,6554,6568,6574,6558$, 


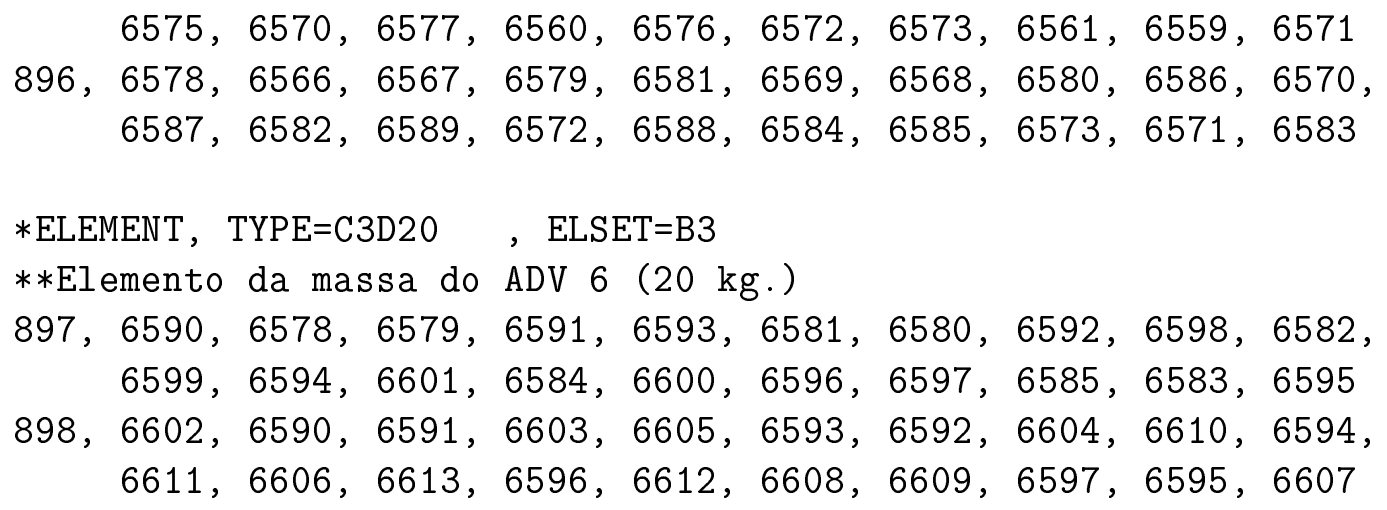

7.8E3

**Material do elemento de união do ADV ao tanque

*MATERIAL , NAME=EL1

*ELASTIC

21E10, .3

$*$ DENSITY

7.8E3

**Material da mola do ADV (20 kg.) 
*MATERIAL , NAME=EL2

$*$ ELASTIC

3.1147E8,

$*$ DENSITY

7.8E3

**Material da massa do ADV (20 kg.)

*MATERIAL , NAME=EL3

*ELASTIC

21E10,

$*$ DENSITY

7.8E3

*SOLID SECTION, ELSET=BO, MATERIAL=ELO

*SOLID SECTION , ELSET=B1, MATERIAL=EL1

$*$ SOLID SECTION , ELSET $=$ B2, MATERIAL=EL2

$*$ SOLID SECTION , ELSET=B3, MATERIAL=EL3

** Pontos onde se observa o deslocamento

$*$ NSET , NSET $=$ Nimp

** Resposta do deslocamento nos pontos da face frente à rua

$1,705,703,974,139,798,796,1085,136,808$, $807,1088,134,815,814,1090, \quad 5, \quad 716, \quad 714,977$

** Pontos de aplicação da carga na face frente à rua

$*$ NSet , NSET $=$ Nf or 99

1

*NSet , NSET=Nfor 100

705

$*$ NSet , NSET=Nfor 101

703

$\ldots \ldots \ldots \ldots \ldots$

(n.

716

*NSet , NSET=Nfor 117

714

$*$ NSet , NSET=Nfor 118

977

** Face frente à rua

** Ponto 22, nos-1

$*$ AMPLITUDE , NAME $=$ A99

$0.000000,-0.000047, \ldots 0.009219, \quad-0.000056$ 
** Ponto 43, nos -977

*AMPLITUDE , NAME $=$ A118

$0.000000,-0.000027, \ldots 0.009219, \quad-0.000082$

$*$ STEP , INC $=120$

$*$ DYNAMIC , DIRECT

$0.000156,0.009219$

** Face frente à rua

** Carregamento de forças proporcionais aos sinais de deslocamento *CLOAD, AMPLITUDE $=$ A99

Nfor99, 2, 1000000

$*$ CLOAD, AMPLITUDE $=\mathrm{A} 100$

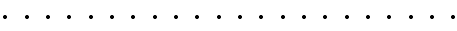

*CLOAD, AMPLITUDE $=$ A117

Nfor117, 2, 1000000

*CLOAD, AMPLITUDE=A118

Nfor118, 2, 1000000

*NODE PRINT, NSET=Nimp

$\mathrm{U}$

*NODE FILE, OUTPUT=3D

$\mathrm{U}$

*END STEP 